\title{
Stochastic Trends and Economic Fluctuations
}

\author{
By Robert G. King, Charles I. Plosser, James H. Stock, \\ AND MARK W. WATSON*
}

\begin{abstract}
Are business cycles mainly the result of permanent shocks to productivity? This paper uses a long-run restriction implied by a large class of real-business-cycle models - identifying permanent productivity shocks as shocks to the common stochastic trend in output, consumption, and investment - to provide new evidence on this question. Econometric tests indicate that this common-stochastic-trend / cointegration implication is consistent with postwar U.S. data. However, in systems with nominal variables, the estimates of this common stochastic trend indicate that permanent productivity shocks typically explain less than half of the business-cycle variability in output, consumption, and investment. (JEL $\mathrm{E} 32, \mathrm{C} 32)$
\end{abstract}

A central, surprising, and controversial result of some current research on real business cycles is the claim that a common stochastic trend-the cumulative effect of permanent shocks to productivity-underlies the bulk of economic fluctuations. If confirmed, this finding would imply that many other forces have been relatively unimportant over historical business cycles, including the monetary and fiscal policy shocks stressed in traditional macroeconomic analysis. This paper shows that the hypothesis of a common stochastic productivity trend has a set of econometric implications that allows us to test for its presence, measure its importance, and extract estimates of its realized value. Applying these procedures to consumption, investment, and output for the postwar United States, we find results that both support and contradict this claim in the real-businesscycle literature. The U.S. data are consis-

\footnotetext{
*University of Rochester, University of Rochester, University of California-Berkeley, and Northwestern University, respectively. The authors thank Ben Bernanke, C. W. J. Granger, Robert Hall, Gary Hansen, Thomas Sargent, James Wilcox, and two referees for helpful discussions and comments and thank Craig Burnside and Gustavo Gonzaga for valuable research assistance. This research was supported in part by the National Science Foundation, the Sloan Foundation, and the John M. Olin Foundation at the University of Rochester.
}

tent with the presence of a common stochastic productivity trend. Such a trend is capable of explaining important components of fluctuations in consumption, investment, and output in a three-variable reduced-form system. However, the common trend's explanatory power drops off sharply when measures of money, the price level, and the nominal interest rate are added to the system. The key implication of the standard real-business-cycle model, that permanent productivity shocks are the dominant source of economic fluctuations, is not supported by these data. Moreover, our empirical results cast doubt on other explanations of the business cycle: estimates of permanent nominal shocks, which are constrained to be neutral in the long run, explain little real activity.

Our econometric methodology can determine the importance of productivity shocks within a wide class of real-business-cycle (RBC) models with permanent productivity disturbances. To explain why this is so, we begin by discussing three features of the research on which our analysis builds. First, there is a long tradition of empirical support for balanced growth in which output, investment, and consumption all display positive trend growth but the consumption: output and investment:output "great ratios" do not (see e.g., Robert Kosobud and Lawrence Klein, 1961). Second, in large part 
because of this ratio stability, most RBC models are one-sector models which restrict preferences and production possibilities so that "balanced growth" occurs asymptotically when there is a constant rate of technological progress. Third, these RBC models imply that permanent shifts in productivity will induce (i) long-run equiproportionate shifts in the paths of output, consumption, and investment and (ii) dynamic adjustments with differential movements in consumption, investment, and output.

The econometric procedures developed here use the models' long-run balancedgrowth implication to isolate the permanent shocks in productivity and then to trace out the short-run effects of these shocks. These econometric procedures rely on the fact that balanced growth under uncertainty implies that consumption, investment, and output are cointegrated in the sense of Robert Engle and Clive Granger (1987). In turn, this means that a cointegrated vector autoregression (VAR) nests log-linear approximations of all RBC models that generate long-run balanced growth. Our empirical analysis is based on such a cointegrated VAR (or vector error-correction model), which is otherwise unrestricted by preferences or technology. Thus, our conclusions can be interpreted as casting doubt on the strong claims emerging from an entire class of real-business-cycle models.

The empirical analysis is structured around three questions. First, what are the cointegration properties of postwar U.S. data, and are these properties consistent with the predictions of balanced growth? Second, how much of the cyclical variation in the data can be attributed to innovations in the common stochastic trends? Third, a natural alternative to RBC models is one in which nominal variables play an important role. Do innovations associated with nominal variables explain important cyclical movements in the real variables?

The empirical results provide robust answers to these questions. First, cointegration tests and estimated cointegrating vectors indicate that the data are consistent with the balanced-growth hypothesis. Sec- ond, in a three-variable model incorporating output, consumption, and investment, the balanced-growth shock explains $60-75$ percent of the variation of output at businesscycle horizons (4-20 quarters). Moreover, the estimated response of the real variables to the balanced-growth shock is similar to the dynamic multipliers implied by simple $\mathrm{RBC}$ models driven by random-walk productivity. Third, these results change significantly when nominal variables are added to the empirical model. When money, prices, and interest rates are added, the balanced-growth shock explains less of the fluctuations in output, from 35 percent to 44 percent depending on the particular specification used. Permanent nominal shocks, identified by imposing long-run neutrality for output, explain little of the variability in the real variables. Much of the short-run variability in output and investment is associated with a shock that has a persistent effect on real interest rates. These results suggest that models that rely solely on permanent productivity or long-run neutral nominal shocks are not capable of capturing important features of the postwar U.S. experience.

The paper is organized as follows. Section I provides theoretical background and reviews recent work on real business cycles. Section II outlines the empirical model and discusses identification. Sections III and IV present the empirical results. Our conclusions are presented in Section V.

\section{Growth and Fluctuations: Theoretical Background}

To fix some ideas and notation, this section outlines a simple real-business-cycle model with permanent productivity shocks. The model is of the general class put forward by Fynn Kydland and Edward Prescott (1982) and is detailed in King et al. (1988). Output, $Y_{t}$, is produced via a constantreturns-to-scale Cobb-Douglas production function:

$$
Y_{t}=\lambda_{t} K_{t}^{1-\theta} N_{t}^{\theta}
$$

where $K_{t}$ is the capital stock and $N_{t}$ repre- 
sents labor input. Total factor productivity, $\lambda_{t}$, follows a logarithmic random walk:

$$
\log \left(\lambda_{t}\right)=\mu_{\lambda}+\log \left(\lambda_{t-1}\right)+\xi_{t}
$$

where the innovations, $\left\{\xi_{t}\right\}$, are independent and identically distributed with a mean of 0 and a variance of $\sigma^{2}$. The parameter $\mu_{\lambda}$ represents the average rate of growth in productivity; $\xi_{t}$ represents deviations of actual growth from this average.

Within the basic neoclassical model with deterministic trends, it is familiar (from Robert Solow [1970]) that per capita consumption, investment, and output all grow at the rate $\mu_{\lambda} / \theta$ in steady state. ${ }^{1}$ The common deterministic trend implies that the great ratios of investment and consumption to output are constant along the steady-state growth path. When uncertainty is added, realizations of $\xi_{t}$ change the forecast of trend productivity equally at all future dates: $E_{t} \log \left(\lambda_{t+s}\right)=E_{t-1}\left(\lambda_{t+s}\right)+\xi_{t}$. A positive productivity shock raises the expected longrun growth path: there is a common stochastic trend in the logarithms of consumption, investment, and output. The stochastic trend is $\log \left(\lambda_{t}\right) / \theta$, and its growth rate is $\left(\mu_{\lambda}+\xi_{t}\right) / \theta$, the analogue of the deterministic model's common growth-rate restriction, $\mu_{\lambda} / \theta$. With common stochastic trends, the great ratios $C_{t} / Y_{t}$ and $I_{t} / Y_{t}$ become stationary stochastic processes.

These theoretical results have a natural interpretation in terms of cointegration. Let $\mathbf{X}_{t}$ be a vector of the logarithms of output, consumption, and investment at date $t$, denoted by $y_{t}, c_{t}$, and $i_{t}$. Each component of $\mathbf{X}_{t}$ is integrated of order one [I(1), or loosely speaking, "nonstationary"] because of the random-walk nature of productivity; yet, the balanced growth implication of the theory implies that the difference between any two elements of $\mathbf{X}_{t}$ is integrated of order zero

\footnotetext{
${ }^{1}$ This follows directly from the economy's commodity resource constraint $\left(Y_{t}=C_{t}+I_{t}\right)$, its investment technology $\left(K_{t+1}=[1-\delta] K_{t}+I_{t}\right.$, with $\delta$ being the rate of depreciation), and the fact that the economy's allocation of time between work and leisure must be constant in steady state.
}

[I(0) or "stationary"]. In Engle and Granger's (1987) terminology, the two linearly independent cointegrating vectors, $\boldsymbol{\alpha}_{1}$ $=(-1,1,0)^{\prime}$ and $\boldsymbol{\alpha}_{2}=(-1,0,1)^{\prime}$ isolate stationary linear combinations of $\mathbf{X}_{t}$ corresponding to the logarithms of the balancedgrowth great ratios.

In this basic one-sector model and variants of it, the precise dynamic adjustment process to a permanent productivity shock depends on the details of preferences and technology. For example, recent RBC research has studied alterations in the investment technology (time-to-build, adjustment costs, and inventories), the production technology (variable capacity utilization, labor indivisibilities, and employment adjustment costs), preferences (nonseparabilities in leisure and durable consumption goods), and serial correlation in the productivity growth process. Two general properties emerge from these investigations. First, the productivity shock sets off transitional dynamics, as capital is accumulated and the economy moves toward a new steady state. During this transition, work effort and the great ratios change temporarily. Second, there is a common stochastic trend in consumption, investment, and output arising from productivity growth. ${ }^{2}$ These two properties motivate the econometric theory and empirical research described in the next sections.

In systems that incorporate both real and nominal variables, additional cointegrating

\footnotetext{
${ }^{2}$ As one example of how an extension of the basic model preserves the stochastic-trend implication, consider the time-to-build investment technology of Kydland and Prescott (1982). All of the stages of investment in their model inherit the common stochastic trend. Similar conclusions hold for the other examples in the text. There are two important categories of RBC models that need not display a single common stochastic trend when there are permanent productivity shocks. Multisector models can have separate productivity trends in each sector, as in John Long and Plosser (1983). Models of stochastic endogenous growth such as those constructed by King and Sergio Rebelo (1988) generate a stochastic trend in the level of productivity when shocks are stationary; with endogenous growth, permanent changes in taxes or in the level of exogenous productivity lead to permanent changes in the growth rates.
} 
relations may plausibly arise. Two are relevant for our empirical analysis. The first is the money-demand relation:

$$
m_{t}-p_{t}=\beta_{y} y_{t}-\beta_{R} R_{t}+v_{t}
$$

where $m_{t}-p_{t}$ is the logarithm of real balances, $R_{t}$ is the nominal interest rate, and $v_{t}$ is the money-demand disturbance. The second is the conventional Fisher relation:

$$
R_{t}=r_{t}+E_{t} \Delta p_{t+1}
$$

where $r_{t}$ is the ex ante real rate of interest, $p_{t}$ is the logarithm of the price level, and $E_{t} \Delta p_{t+1}$ denotes the expected rate of inflation between $t$ and $t+1$. If real balances, output, and interest rates are $I(1)$, while the money-demand disturbance in (3) is $I(0)$, then real balances, output, and nominal interest rates are cointegrated. If the real rate is $I(0)$ and the inflation rate is $I(1)$, then (4) implies that nominal interest rates and inflation are cointegrated. The empirical analysis investigates these cointegrating relations and isolates the common stochastic trends that they imply.

\section{Econometric Methodology}

This section provides an overview of the econometric techniques used to answer the questions posed in the Introduction. The first question, concerning the integration and cointegration properties of the data, can be addressed using techniques that are now familiar. This section therefore focuses on the specification of an econometric model in which the trends and their impulse response functions can be identified and estimated.

Let $\mathbf{X}_{t}$ denote an $n \times 1$ vector of time series. The individual series are assumed to be I(1) (so that they must be differenced before they are stationary) and to have the Wold representation:

$$
\Delta \mathbf{X}_{t}=\mu+\mathrm{C}(\mathrm{L}) \varepsilon_{t}
$$

where $\varepsilon_{t}$ is the vector of one-step-ahead linear forecast errors in $\mathbf{X}_{t}$ given information on lagged values of $\mathbf{X}_{t}$. The $\varepsilon_{t}$ 's are serially uncorrelated with a mean of zero and covariance matrix $\boldsymbol{\Sigma}_{\varepsilon}$. Equation (5) is a reduced-form relation and, except for purposes of forecasting, is of little inherent interest. What is of interest is the set of structural relations that leads to (5) and the primary purposes of this section are to discuss (i) how the balanced-growth and other cointegration restrictions outlined in the last section restrict this set of structural relations and (ii) how these restrictions can be exploited to draw inferences about structural relations from consistent estimators of $\mathbf{C}(\mathrm{L})$ and $\boldsymbol{\Sigma}_{\varepsilon}$.

To be specific, consider a structural model of the form

$$
\Delta \mathbf{X}_{t}=\boldsymbol{\mu}+\boldsymbol{\Gamma}(\mathrm{L}) \boldsymbol{\eta}_{t}
$$

where $\boldsymbol{\eta}_{t}$ is a $n \times 1$ vector of serially uncorrelated structural disturbances with a mean of zero and a covariance matrix $\boldsymbol{\Sigma}_{\boldsymbol{\eta}}$. The reduced form of (6) will be of the form (5) with $\boldsymbol{\varepsilon}_{t}=\boldsymbol{\Gamma}_{0} \boldsymbol{\eta}_{t}$ and $\mathbf{C}(\mathrm{L})=\Gamma(\mathrm{L}) \Gamma_{0}^{-13}$

The identification problem can now be stated as follows: under what conditions is it possible to deduce the structural disturbances $\boldsymbol{\eta}_{t}$ and matrix of lag polynomials $\boldsymbol{\Gamma}(\mathrm{L})$ from the reduced-form errors $\varepsilon_{t}$ and matrix of lag polynomials $\mathrm{C}(\mathrm{L})$ ? In the classical literature on simultaneous-equation models, the identification problem is solved by postulating that certain blocks of $\Gamma(\mathrm{L})$ are zero, so that some of the $X$ 's are exogenous or predetermined. In linear rationalexpectations models, the identification problem is solved by imposing cross-equation restrictions on the various elements of $\boldsymbol{\Gamma}(\mathrm{L})$, as described, for example in Kenneth Wallis (1980) and Lars Hansen and Thomas Sargent (1980). The literature on vector autoregressive models addresses the identification problem by imposing restrictions on the covariance matrix $\Sigma_{\eta}$ and the matrix of structural impact multipliers, $\boldsymbol{\Gamma}_{0}$. For example, in his classic paper on vector autoregressions, Christopher Sims (1980) assumes that $\Sigma_{\eta}$ is diagonal and that $\boldsymbol{\Gamma}_{0}$ is lower

\footnotetext{
${ }^{3}$ This assumes that the structural disturbances lie in the space spanned by current and lagged values of $\mathbf{X}_{t}$.
} 
triangular, assumptions analogous to a Wold causal chain; Olivier Blanchard and Watson (1986) modify Sims's original procedure by imposing restrictions on $\Gamma_{0}$ analogous to those appearing in static simultaneousequation models.

In this paper, identification is achieved through two sets of restrictions. First, the cointegration restrictions impose constraints on the matrix of long-run multipliers $\Gamma(1)$ $\left(=\sum_{i=0}^{\infty} \Gamma_{i}\right)$ in (6). This identifies the permanent components. Second, the innovations in the permanent components are assumed to be uncorrelated with the innovations to the remaining transitory components. This identifies the dynamic response of the economic variables to the permanent innovations. A concise algebraic summary of the identification scheme is given in the Appendix, with a more extensive discussion in King et al. (1987); here, we outline the major ideas and relate our procedure to other recent work.

Consider the three-variable model with $\mathbf{X}_{t}=\left(y_{t}, c_{t}, i_{t}\right)^{\prime}$. Because there are two cointegrating vectors, there is only one permanent innovation, the balanced-growth innovation $\eta_{t}^{1}$. This shock corresponds to $\xi_{t}$ in the neoclassical model of Section I. The other two shocks, $\eta_{t}^{2}$ and $\eta_{t}^{3}$, have only transitory effects on $\mathbf{X}_{t}$. Thus, the first identification restriction (the balanced-growth cointegrating vectors) implies that the matrix of long-run multipliers is

$$
\boldsymbol{\Gamma}(1)=\left[\begin{array}{lll}
1 & 0 & 0 \\
1 & 0 & 0 \\
1 & 0 & 0
\end{array}\right]
$$

where the values of the coefficients in the first column of $\boldsymbol{\Gamma}(1)$ are normalized to 1 to fix the scale of $\eta_{t}^{1}$. Equation (7) serves to identify the balanced-growth shock as the common long-run component in $\mathbf{X}_{t}$, since the innovation in the long-run forecast of $\mathbf{X}_{t}$ is $\left(\begin{array}{lll}1 & 1 & 1\end{array}\right)^{\prime} \eta_{t}^{1}=\mathbf{C}(1) \boldsymbol{\varepsilon}_{t}$, which can be calculated directly from the reduced form (5). The second restriction, that $\eta_{t}^{1}$ is uncorrelated with $\eta_{t}^{2}$ and $\eta_{t}^{3}$, is used to determine the dynamic effect of $\eta_{t}^{1}$ on $\mathbf{X}_{t}$, that is, to identify the first column of $\boldsymbol{\Gamma}(\mathrm{L})$. The reason this assumption is needed is clear: the impulse responses given by the first column of $\boldsymbol{\Gamma}(\mathrm{L})$ are the partial derivatives of $\Delta \mathbf{X}_{t+k}$ with respect to $\eta_{t}^{1}$. The second restriction specifies what is being held constant in computing these partial derivatives.

Another way to motivate these identifying restrictions is to rewrite the model in terms of the stationary variables $\mathbf{Z}_{t}=\left(\Delta y_{t}\right.$, $\left.c_{t}-y_{t}, i_{t}-y_{t}\right)^{\prime}$. The productivity shock, $\eta_{t}^{1}$, has a long-run effect on $y_{t}$ but no long-run effect on the stationary ratios, $c_{t}-y_{t}$ and $i_{t}-y_{t}$. Thus, $\eta_{t}^{1}$ can be identified as the innovation in the long-run component of the first element of $\mathbf{Z}_{t}$. The other two disturbances, $\eta_{t}^{2}$ and $\eta_{t}^{3}$, have temporary effects on $y_{t}$ and the ratios.

Blanchard and Danny Quah (1989) used a special case of this identification scheme to analyze $\tilde{\mathbf{Z}}_{t}=\left(\Delta y_{t}, u_{t}\right)^{\prime}$, where $u_{t}$ was the unemployment rate, which they assumed to be I(0). Their disturbances were $\tilde{\eta}_{t}^{1}$ a "supply shock," and $\tilde{\eta}_{t}^{2}$, a "demand shock." These shocks were restricted to be uncorrelated, and only the supply shock, $\tilde{\eta}_{t}^{1}$, was allowed to have a long-run effect on $y_{t}$. Thus, except for the fact that their system is bivariate and ours is trivariate, the identifying restrictions are identical. Indeed, if we eliminate one of the ratios, so that our model is bivariate, our identifying restrictions are formally equivalent to those used by Blanchard and Quah.

This equivalence highlights what we consider to be two practical advantages of the empirical specification employed here. First, work in the tradition of Milton Friedman (1957) links consumption to permanent income. This suggests that the emphasis on real flow variables, rather than on unemployment and output as in Blanchard and Quah, arguably will result in better estimates of the trend components of output and the parameters of the structural model. ${ }^{4}$ Second, our application is to multivariate systems rather than bivariate systems. This

\footnotetext{
${ }^{4}$ This notion, that consumption might provide a good measure of permanent income, has been recently exploited by John Cochrane and Argia Sbordone (1988), Andrew Harvey and James Stock (1988), Eugene Fama (1990), and Cochrane (1990).
} 
has two advantages: first, more macroeconomic variables are used to estimate the common trends, and second, by allowing for a wider range of shocks, a richer set of alternative models is considered.

To introduce nominal shocks, the threevariable real model is augmented by real balances, nominal interst rates, and inflation. The resulting six-variable model has three common stochastic trends, and this makes identification more complicated, since the individual permanent innovations must be sorted out. We use a version of Sims's (1980) procedure for this purpose.

The general identification problem can be described as follows. Suppose that there are $k$ common stochastic trends driving the $n \times 1$ vector $\mathbf{X}_{t}$. Partition the vector of structural disturbances $\boldsymbol{\eta}_{t}$ into two components, $\boldsymbol{\eta}_{t}=$

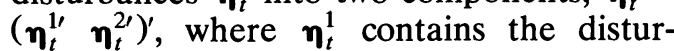
bances that have permanent effects on the components of $\mathbf{X}_{t}$ and where $\boldsymbol{\eta}_{t}^{2}$ contains disturbances that have only temporary effects. (In our six-variable model, $k=3$ and $\eta_{t}^{1}$ is a $3 \times 1$ vector containing the balancedgrowth shock, a long-run neutral inflation shock, and a real-interest-rate shock.) Partition $\boldsymbol{\Gamma}(1)$ conformably with $\boldsymbol{\eta}_{t}$ as $\boldsymbol{\Gamma}(1)=$ [A 0], where $\mathbf{A}$ is the $n \times k$ matrix of long-run multipliers for $\boldsymbol{\eta}_{t}^{1}$ and $\mathbf{0}$ is an $n \times(n-k)$ matrix of zeros corresponding to the longrun multipliers for $\boldsymbol{\eta}_{t}^{2}$. The matrix of long-run multipliers is determined by the condition that its columns are orthogonal to the cointegrating vectors, and $\mathbf{A} \eta_{t}^{1}$ represents the innovations in the long-run components of $\mathbf{X}_{t}$.

Identification of the individual elements of $\boldsymbol{\eta}_{t}^{1}$ becomes more complicated when there is more than one permanent innovation, because the unique influence of each permanent component needs to be isolated. Formally, while the cointegration restrictions identify the permanent innovations $\mathbf{A} \boldsymbol{\eta}_{t}^{1}$, they fail to identify $\boldsymbol{\eta}_{t}^{1}$ because $\mathbf{A} \boldsymbol{\eta}_{t}^{1}=$ (AP) $\left(\mathbf{P}^{-1} \boldsymbol{\eta}_{t}^{1}\right)$ for any nonsingular matrix $\mathbf{P}$. The following restrictions are used to identify the model. First, as in the model with $k=1$, we assume that $\boldsymbol{\eta}_{t}^{1}$ and $\boldsymbol{\eta}_{t}^{2}$ are uncorrelated. Second, the permanent shocks, $\eta_{t}^{1}$, are assumed to be mutually uncorrelated. Third, $\mathbf{A}$ is assumed to be lower triangular, which permits writing $\mathbf{A}=\tilde{\mathbf{A}} \mathbf{I}$, where $\tilde{\mathbf{A}}$ is a matrix with no unknown parameters (analogous to the vector of 1's in the $k=1$ model) and $\boldsymbol{I}$ is a $k \times k$ lower triangular matrix. As will become clear in the next section, $\tilde{\mathbf{A}}$ can be chosen in a way that associates each shock with a familiar economic mechanism: the first disturbance is interpreted as a balanced-growth shock, the second is a long-run neutral inflation shock and the third is a permanent real-interest-rate shock. Finally, the constrained reduced form is estimated as a VAR with error-correction terms [i.e., a vector error-correction model (VECM)].

\section{Empirical Results}

\section{A. The Data}

The data are quarterly U.S. observations on real aggregate national income account flow variables, the money supply, inflation, and a short-term interest rate. The three aggregate real flow variables are the logarithms of per capita real consumption expenditures $(c)$, per capita gross private domestic fixed investment $(i)$, and per capita "private" gross national product $(y)$, defined as total gross national product less real total government purchases of goods and services. The measure of the money supply used is M2 (currency, demand deposits, and savings deposits, per capita in logarithms; $m$ ). The price level is measured by the implicit price deflator for our measure of private GNP (in logarithms; $p$ ) and the interest rate $(R)$ is the three-month U.S. Treasury bill rate. Regressions were run over 1949:1-1988:4 for statistical procedures that involved only real flows. To avoid observations that occurred during periods of price controls, the Korean War, and the Treasury-Fed accord, the regressions were run over 1954:1-1988:4 when money, interest rates, or prices were involved. Data prior to $1949: 1$ (respectively, 1954:1) were used as initial observations in regressions that contain lags. ${ }^{5}$

\footnotetext{
${ }^{5}$ All data were obtained from Citibase. Using the Citibase mnemonics for the series, the precise definitions of the variables are GC82 (consumption), GIF82 (investment), and (GNP82-GGE82) (real private output). The Citibase M2 series (FM2) was used for
} 
Because the national product measure is not the standard one, we have graphed the logarithm of the real variables $(y, c, i$, and $m-p$ ) in Figure 1A. These plots show the familiar growth and cyclical characteristics of the data. Output, consumption, and investment display strong upward trends. Investment is the most volatile component, followed by output and then consumption. Real balances $(m-p)$ also display an upward trend. Figure 1B plots the logarithm of the consumption:output ratio $(c-y)$ and the logarithm of the investment:output ratio $(i-y)$. Over the postwar period, these ratios display the stability reported by prior researchers; it is easy to view them as fluctuating around a constant mean. This suggests that the growth evident in Figure 1 occurs in a manner that is "balanced" between investment and consumption.

\section{B. Integration and Cointegration Properties of the Data}

Univariate analysis of these six variables indicates that the real flow variables, $y, c$, and $i$ can be characterized as $\mathrm{I}(1)$ processes with positive drift, and that $R$, price inflation $(\Delta p)$, and nominal money growth $(\Delta m)$ can be characterized as $\mathrm{I}(1)$ processes without drift. These results are consistent with the large literature on the "unit-root" properties of U.S. macroeconomic time-series. ${ }^{6}$

1959:1-1988:4; the earlier M2 data were formed by splicing the M2 series reported in Banking and Monetary Statistics, 1941-1970 (Board of Governors of the Federal Reserve System, 1976) to the Citibase data in January 1959 . The monthly data were averaged to obtain the quarterly observations. The price deflator was obtained as the ratio of nominal private GNP (the difference between Citibase series GNP and GGE) to real private GNP (the difference between Citibase series GNP82 and GGE82). The interest rate is FYGM3. It is measured as an annual percentage (a typical value is 10.0 percent). Price inflation was also measured as an annual percentage $\left[400 \ln \left(P_{t} / P_{t-1}\right)\right]$. Output, consumption, investment, and money are determined on a per capita basis using total civilian noninstitutional population (P16).

${ }^{6}$ Because the techniques and results are now familiar, they are omitted here; interested readers are referred to an earlier version of this paper (King et al., 1987) for details.
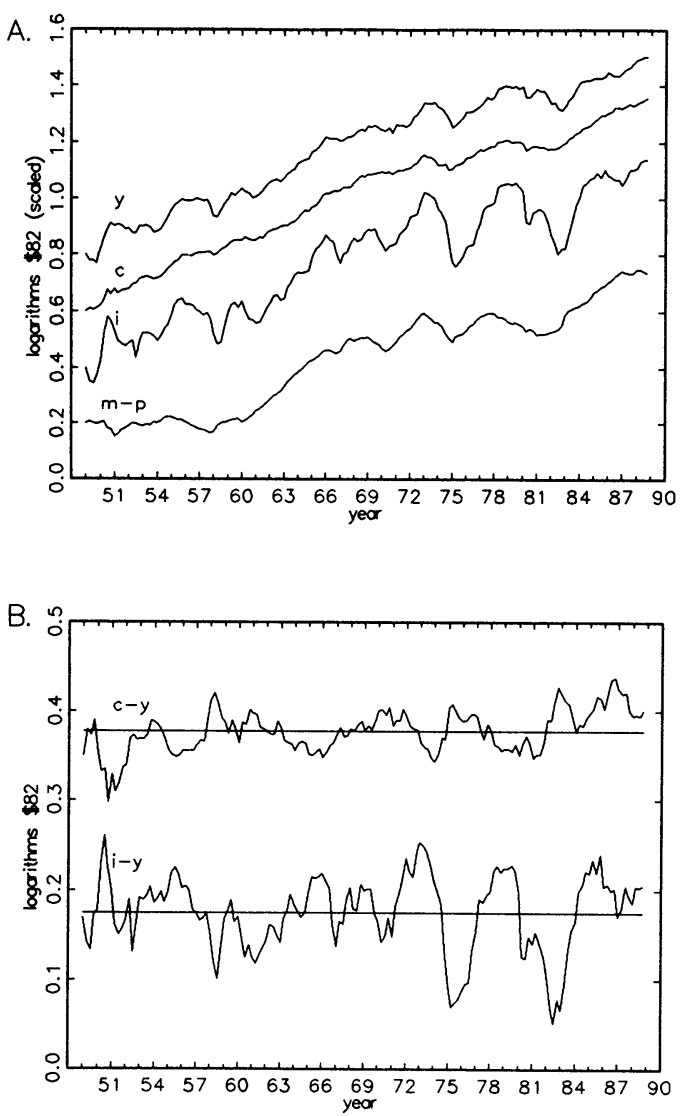

Figure 1. A) Logarithms of Private Output

$(y)$, Consumption $(c)$, InVestment $(i)$, AND Real Money Balances $(m-p)$;

B) LOGARITHMS OF THE CONSUMPTION:OUTPUT $(c-y)$ AND InVESTMENT:OUTPUT $(i-y)$ Ratios Note: To facilitate graphing, constants were added to the logarithms of the variables. The horizontal lines in part $\mathrm{B}$ are the means of the (constant-adjusted) variables.

The balanced-growth conditions also appear to be consistent with the data: we can reject the presence of unit-root components in the great ratios. Augmented DickeyFuller $t$ statistics $\left(\hat{\tau}_{\tau}\right.$, with five lags; see David Dickey and Wayne Fuller, 1979) testing for a unit autoregressive root in $c-y$ and $i-y$ have values of -4.21 and -3.99 , respectively; both are significant at the 1percent level, suggesting that $(c, y)$ and $(i, y)$ are cointegrated. The log of real balances, $m-p$, appears to be an I(1) process with drift, even though both $m$ and $p$ can be 
Table 1-Cointegration Statistics: Three-Variable Model, $(y, c, i), 1949: 1-1988: 4$

\begin{tabular}{|c|c|c|c|c|c|}
\hline \multicolumn{6}{|c|}{$\begin{array}{l}\text { A. Results from Unrestricted Levels Vector Autoregressions: } \\
\text { Largest Eigenvalues of Estimated Companion Matrix }\end{array}$} \\
\hline \multicolumn{3}{|c|}{ VAR(6) with constant } & \multicolumn{3}{|c|}{ VAR(6) with constant and trend } \\
\hline Real & Imaginary & Modulus & Real & Imaginary & Modulus \\
\hline 1.00 & 0.00 & 1.00 & 0.97 & 0.00 & 0.97 \\
\hline 0.83 & 0.19 & 0.85 & 0.83 & 0.18 & 0.85 \\
\hline 0.83 & -0.19 & 0.85 & 0.83 & -0.18 & 0.85 \\
\hline-0.62 & 0.46 & 0.77 & -0.62 & 0.46 & 0.77 \\
\hline-0.62 & -0.46 & 0.77 & -0.62 & -0.46 & 0.77 \\
\hline 0.50 & 0.50 & 0.71 & 0.49 & 0.49 & 0.69 \\
\hline \multicolumn{2}{|c|}{ Log likelihood: } & & & $2,200.95$ & \\
\hline \multicolumn{6}{|c|}{ oot Statistics } \\
\hline Statistic & Value & \multicolumn{2}{|c|}{$P$ value } & \multicolumn{2}{|c|}{ Null/alternative } \\
\hline$J_{\tau}(0)$ & 35.4 & \multicolumn{2}{|c|}{0.13} & \multicolumn{2}{|c|}{3 unit roots /at most 2 unit roots } \\
\hline$q_{\tau}^{\mathrm{f}}(3,2)$ & -29.4 & \multicolumn{2}{|c|}{0.21} & \multicolumn{2}{|c|}{3 unit roots / at most 2 unit roots } \\
\hline$q_{\tau}^{\mathrm{f}}(3,1)$ & -29.4 & \multicolumn{2}{|c|}{$<0.01$} & \multicolumn{2}{|c|}{3 unit roots / at most 1 unit root } \\
\hline
\end{tabular}

Log likelihood (3 unit roots): $2,183.27$

Log likelihood (2 unit roots): $2,193.11$

Log likelihood (1 unit root): $2,199.43$

Log likelihood (0 unit roots): 2,200.95

\section{Estimated Cointegrating Vectors}

\begin{tabular}{lrrrrr} 
& \multicolumn{2}{c}{ Null hypothesis } & & \multicolumn{2}{c}{ Estimates } \\
\cline { 2 - 3 } \cline { 5 - 6 } Variable & $\alpha_{1}$ & $\alpha_{2}$ & & $\hat{\alpha}_{1}$ & $\hat{\alpha}_{2}$ \\
\hline$c$ & 1 & 0 & $1.00^{\mathrm{a}}$ & $0.00^{\mathrm{a}}$ \\
$i$ & 0 & 1 & & $0.00^{\mathrm{a}}$ & $1.00^{\mathrm{a}}$ \\
$y$ & -1 & -1 & & -1.058 & -1.004 \\
& & & $(0.026)$ & $(0.038)$
\end{tabular}

Wald test of balanced growth restrictions: $X_{[2]}^{2}=4.96(P=0.08)$

Notes: Values in parentheses are $P$ values (for the test statistics) or standard errors (for the estimators). The roots and likelihoods in part A correspond to an unrestricted VAR(6) in levels. The multivariate unit-root tests in part B, which are described in detail in footnote 7, were computed from VAR(6)'s in levels. $J_{\tau}(r)$ is Johansen's (1988) test of the null of $r$ cointegrating vectors against more than $r$ cointegrating vectors, and $q_{\tau}^{\mathrm{f}}(k, m)$ is Stock and Watson's (1988) test of the null of $k$ unit roots in the multivariate system against the alternative of $m(m<k)$ unit roots, where " $\tau$ " denotes linear detrending. The log likelihoods in part B are for models that include a constant and linear time trend. Part $\mathrm{C}$ reports the cointegrating vectors for $(c, i, y)$, estimated by Stock and Watson's (1989) dynamic OLS (with a constant, five leads, and five lags) procedure. The $t$ statistics formed using the standard errors have asymptotic normal distributions. The Wald statistic, which tests whether the cointegrating vectors lie in the hypothesized subspace, is computed using the dynamic OLS estimates and standard errors described in footnote 8 .

${ }^{\text {a }}$ Normalized.

characterized as $\mathrm{I}(2)$ processes. (The $\hat{\tau}_{\tau}$ statistic for $\Delta(m-p)$ is significant at the 1-percent level). The best characterization of the real interest rate is unclear. The ex post real rate, $R-\Delta p$, has a sample AR(1) coefficient equal to 0.86 , suggesting stationary behavior, but the augmented Dickey-Fuller $t$ statistic ( $\hat{\tau}_{\mu}$, with five lags) is only -1.8 , which is consistent with a unit root in the real rate.

Tables 1-3 present a variety of statistics calculated from multivariate systems, start- 
ing with the results for the three-variable $(y, c, i)$ model. Panel A of Table 1 shows the largest eigenvalues from the companion matrix of an estimated VAR(6). The model with one common stochastic trend (balanced growth) implies that the companion matrix should have one unit eigenvalue, corresponding to the common trend, and all the other eigenvalues should be less than 1 in modulus. The point estimates are in accord with this prediction. Panel B presents formal tests for cointegration using procedures developed by Soren Johansen (1988) and Stock and Watson (1988). Both procedures take as their null hypothesis that the data are integrated but not cointegrated, so that there are three unit roots in the companion matrix. The first two rows of panel B test this against an alternative of at most two unit roots, while the third row tests the null against the sharper alternative of at most one unit root. The results are consistent with the one-unit-root (one common trend) specification. ${ }^{7}$

The final panel in Table 1 presents maximum-likelihood estimates of the cointegrating vectors, conditional on the presence of one unit root in the VAR, computed using the dynamic ordinary least-squares (OLS) procedure of Stock and Watson (1989). The point estimates are close to $(1,0,-1)$ and $(0,1,-1)$, the values that imply balanced

\footnotetext{
${ }^{7}$ The multivariate unit-root tests in Tables 1-3 are based on the $J_{\mu}(r), J_{\tau}(r), q_{\mu}^{\mathrm{f}}(k, m)$, and $q_{\tau}^{\mathrm{f}}(k, m)$ statistics. The $J(r)$ statistics are Johansen's (1988) test of the null of $r$ cointegrating vectors against more than $r$ cointegrating vectors, and the $q^{\mathrm{f}}(k, m)$ statistics are Stock and Watson's (1988) test of the null of $k$ unit roots in the multivariate system against the alternative of $m(m<k)$ unit roots; " $\mu$ " and " $\tau$ " subscripts denote the tests computed using demeaned data and data that have been both demeaned and linearly detrended, respectively. (Detrending is appropriate if the series have a nonzero drift under the null.) Asymptotic critical values for $q_{\mu}^{\mathrm{f}}$ and $q_{\tau}^{\mathrm{f}}$ are taken from Stock and Watson (1988). Asymptotic $p$ values for $J_{\mu}$ and $J_{\tau}$ differ from those tabulated in Johansen (1988) because of the demeaning/detrending. It is straightforward to derive and to compute the asymptotic null distribution of $J_{\mu}$ and $J_{\tau}$ using the results in Sims et al. (1990). We have done this, and the $p$ values shown in the tables are based on these asymptotic distributions. All multivariate tests were computed using six lagged levels, which these procedures parameterize as five lags in first differences and a single lagged level.
}

growth in output, consumption, and investment. These balanced-growth restrictions impose two constraints on the cointegrating vectors. In Table 1 , these restrictions are tested using a Wald statistic based on the dynamic OLS point estimates and standard errors; under the null hypothesis, this statistic has an asymptotic chi-square distribution with two degrees of freedom. Although the restriction is rejected at the 10-percent (but not the 5-percent) level, the estimated cointegrating vector is broadly consistent with the balanced-growth prediction. ${ }^{8}$

Table 2 explores two sets of cointegrating relations suggested by the nonstationarity of the nominal and real interest rates. Table $2 \mathrm{~A}$ reports an estimated cointegrating relation between real balances, output, and nominal interest rates. ${ }^{9}$ The estimate of the long-run income elasticity is close to unity (although statistically significantly larger than 1); the estimated interest rate semielasticity is small but statistically significantly less than zero.

\footnotetext{
${ }^{8}$ The cointegrating vectors reported in Tables $1-3$, and the estimated cointegrating vectors used as the basis of the VAR analysis in Tables 4-6, were estimated using the Stock and Watson (1989) dynamic OLS procedure, which is asymptotically equivalent to the Gaussian maximum-likelihood procedure for a triangular error-correction system. If there are $r$ cointegrating vectors, then there are $r$ regression equations; each equation has $n-r$ regressors in levels (where $n$ is the number of variables), a constant, and $m$ leads, $m$ lags, and the contemporaneous values of the differences of right-hand-side levels variables. Standard errors, calculated using a VAR(4) estimator of the spectral density matrix of the errors in these $r$ equations, are given in parentheses in Tables 1-3. All results are based on $m=5$; to allow for the leads, the dynamic OLS regressions end at 1987:3 (all other regressions go through 1988:4). Wald statistics computed using the estimated covariance matrix have the usual large-sample chi-square distributions.

The log likelihoods provided in Table 1 and subsequent tables are provided as a guide for readers interested in exploring the shape of the likelihood surface. It should be stressed that, because of the hypothesized unit roots, the usual chi-square inference does not always apply to likelihood-ratio statistics computed from the reported values.

${ }^{9}$ See Robert Lucas (1988), Dennis Hoffman and Robert Rasche (1989), and Benjamin Friedman and Kenneth Kuttner (1990) for recent empirical investigations of the stability of long-run money demand.
} 
TABle 2-Estimated Cointegrating Vectors

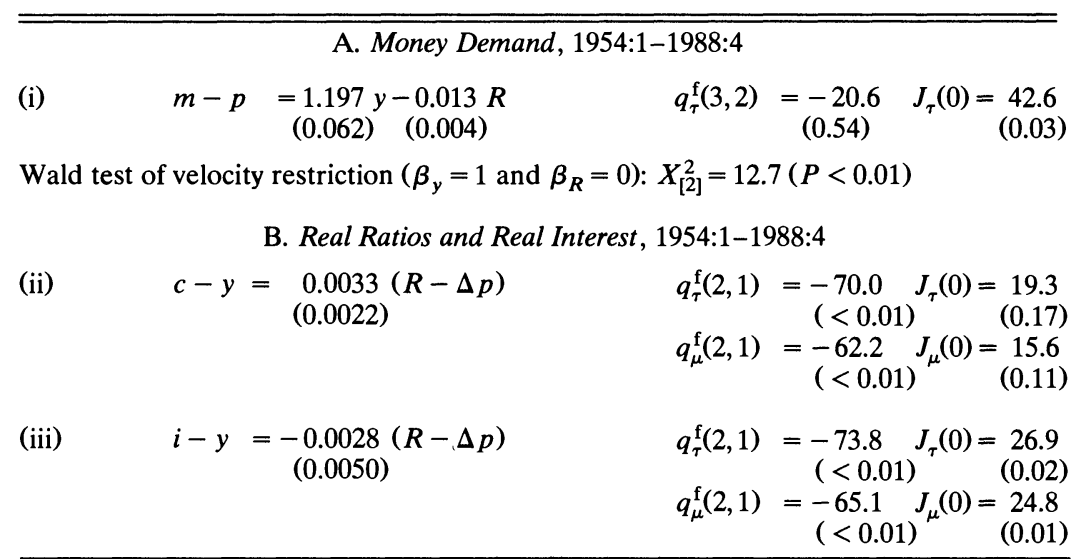

Notes: Values in parentheses are $P$ values (for the test statistics) or standard errors (for the estimators). The cointegrating vectors (i)-(iii) were estimated by dynamic OLS (with five leads and five lags), including a constant in the regression, equation-by-equation. The $q_{\mu}^{\mathrm{f}}$ and $J_{\mu}$ tests are computed using demeaned data (see footnote 7 ). The Wald statistic, which tests whether the cointegrating vectors lie in the hypothesized subspace, is computed using the dynamic OLS estimates and standard errors described in footnote 8 .

The second issue examined in Table 2 is the possibility that the consumption:output and investment:output ratios might exhibit permanent shifts resulting from permanent shifts in real rates. Estimated bivariate cointegrating relations $(c-y)=\phi_{1}(R-\Delta p)$ and $(i-y)=\phi_{2}(R-\Delta p)$ are shown in Table 2B. As predicted by the long-run theory of the growth model, for example, a higher real interest rate lowers the share of product going into investment and, symmetrically, raises the share of consumption. However, the long-run effects are imprecisely estimated and small: a permanent increase in the annual real rate of one percentage point is associated with an increase in the consumption:output ratio of 0.3 percentage points.

The cointegration properties of the sixvariable system $(y, c, i, m-p, R, \Delta p)$ are investigated in Table 3 . The theoretical analysis suggests three stochastic trends in the system: a balanced-growth trend, an inflation/money-growth trend and, possibly, a real-interest-rate stochastic trend. Equivalently, three cointegrating relations should be present in the system: two (interest-rateadjusted) balanced-growth relations and a long-run money-demand relation. The $q_{\tau}^{\mathrm{f}}(6,3)$ statistic reported at the bottom of Table 3A provides some evidence for the three-trend specification, rejecting six unit roots against three with a $P$ value of 0.11 .

The Wald tests in Table 3B investigate various hypotheses about the cointegrating vectors, under the maintained hypothesis that the number of cointegrating vectors is correctly specified. The first hypothesis (Table 3B, row 1) is that the cointegrating vectors are the balanced-growth and money-demand cointegrating vectors. This hypothesis is rejected at the 10-percent level but not at the 5-percent level. Despite this formal rejection at the 10 -percent level, we interpret the balanced-growth/moneydemand cointegrating restrictions as providing a good qualitative description of the cointegrating vectors for the system. The remaining lines of Table $3 \mathrm{~B}$ investigate alternative cointegration restrictions. There is strong evidence against a fourth cointegrating vector implying stationary real rates (line 2) and against the stationary velocity model, even permitting cointegration between the great ratios and real rates (line 4). The evidence is weakest against the hypothesis 
Table 3-Cointegration Statistics: Six-Variable Model $(y, c, i, m-p, R, \Delta p), 1954: 1-1988: 4$

\begin{tabular}{lccr}
\hline \hline & \multicolumn{2}{c}{ A. Estimated Cointegrating Vectors } & \\
Variable & $\hat{\alpha}_{1}$ & $\hat{\alpha}_{2}$ & $\hat{\alpha}_{3}$ \\
\hline$c$ & $1.00^{\mathrm{a}}$ & $0.00^{\mathrm{a}}$ & $0.00^{\mathrm{a}}$ \\
$i$ & $0.00^{\mathrm{a}}$ & $1.00^{\mathrm{a}}$ & $0.00^{\mathrm{a}}$ \\
& & & \\
$m-p$ & $0.00^{\mathrm{a}}$ & $0.00^{\mathrm{a}}$ & $1.00^{\mathrm{a}}$ \\
$y$ & -1.118 & -1.120 & -1.152 \\
& $(0.050)$ & $(0.083)$ & $(0.063)$ \\
$R$ & 0.004 & 0.002 & 0.009 \\
& $(0.003)$ & $(0.005)$ & $(0.004)$ \\
$\Delta p$ & 0.004 & 0.006 & 0.002 \\
& $(0.003)$ & $(0.004)$ & $(0.003)$ \\
\end{tabular}

$q_{\tau}^{\mathrm{f}}(6,3)=-27.5(P$ value $=0.11)$

Log likelihood $=2,826.54$

\section{B. Tests of Restrictions on Cointegrating Vectors}

\begin{tabular}{lcc} 
Null hypothesis & $d . f$. & Wald test \\
\hline$(c-y),(i-y), m-p-\beta_{y} y+\beta_{R} R$ & 7 & $12.6(0.08)$ \\
$(c-y),(i-y), m-p-\beta_{y} y+\beta_{R} R, R-\Delta p$ & 6 & $40.1(<0.01)$ \\
$(c-y)-\phi_{1}(R-\Delta p),(i-y)-\phi_{2}(R-\Delta p)$, & 5 & $7.6(0.18)$ \\
$m-p-\beta_{y}+\beta_{R} R$ & & \\
$(c-y)-\phi_{1}(R-\Delta p),(i-y)-\phi_{2}(R-\Delta p), m-p-y$ & 7 & $42.0(<0.01)$ \\
\hline
\end{tabular}

Notes: Values in parentheses are $P$ values (for the test statistics) or standard errors (for the estimators). Part A reports dynamic OLS estimates for the three-equation system. Part B reports tests of whether the cointegrating vectors fall in the hypothesized subspace, conditional on the number of cointegrating vectors. The Wald statistics, which test whether the cointegrating vectors lie in the hypothesized subspace, are computed using the dynamic OLS estimates and standard errors described in footnote 8.

${ }^{\text {a }}$ Normalized.

that the great ratios and real rates are cointegrated, combined with the money-demand cointegrating vector (line 3$)^{10}$

Taken together, these results suggest that a money-demand cointegrating relation is consistent with the observed behavior of the

${ }^{10}$ To check robustness, the cointegrating vectors in Tables 1, 2, 3, and 6 were also estimated using Johansen's (1988) maximum-likelihood estimate (MLE) for a vector error-correction model with five lagged differences, one lagged level, and a constant. The Johansen MLE point estimates (available from the authors upon request) are similar to the dynamic OLS point estimates. For example, the Johansen MLE of the money-demand equation is $m-p=1.134 y-$ $0.0093 R$ [cf. model (i) in Table 2]. time-series. There is some evidence that the shares of consumption and investment move with permanent shifts in the real rate. Yet, this effect is negligibly small in the long run, and the hypothesis of "balanced growth" also appears to be generally consistent with the data.

\section{A Three-Variable System of Real Flow Variables}

The results for the three-variable system are based on an estimated VECM using eight lags of the first differences of $y, c$, and $i$ with an intercept and the two theoretical error-correction terms, $c-y$ and $i-y$. The 

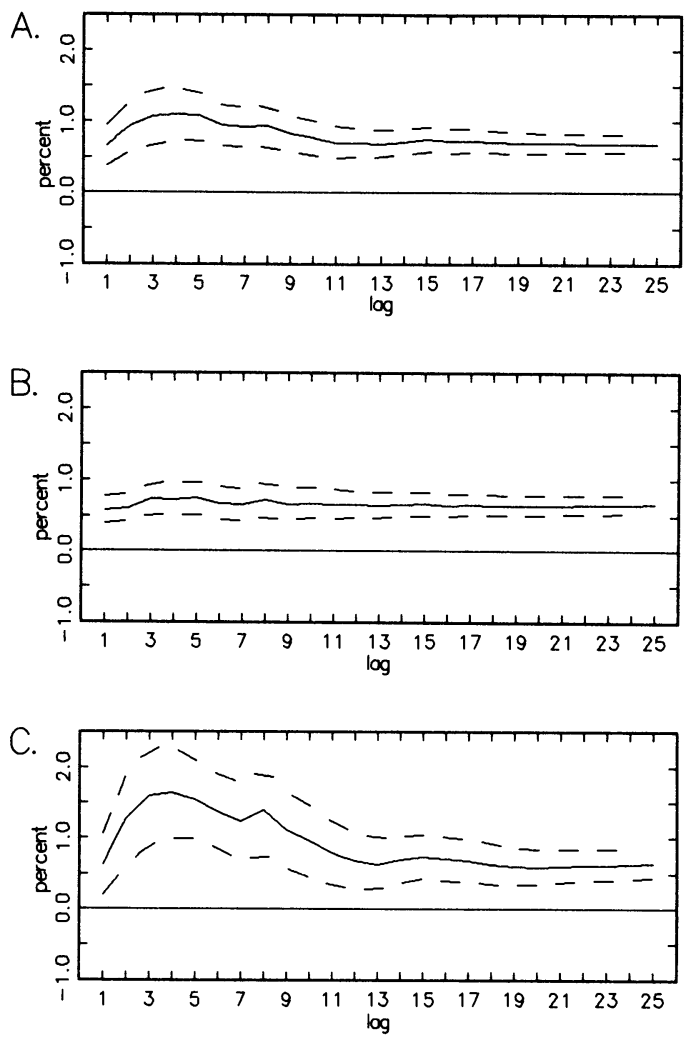

Figure 2. Responses in a Three-Variable Model to a One-Standard-Deviation Shock in the Real Permanent Component:

A) Response of Log Output; B) Response of Log Consumption; C) Response of Log InVEstMent

only identifying assumption needed to analyze the dynamics of the system is that the permanent shock is uncorrelated with the transitory shocks. The impulse response of $y, c$, and $i$ to an innovation of one standard deviation in the common trend is plotted in Figure 2, together with one-standarddeviation confidence bands. ${ }^{11}$ (The standard deviation of the balanced-growth shock is 0.7 percent, and as discussed in Section II, the system is normalized so that a one-unit

\footnotetext{
${ }^{11}$ The standard errors for the impulse response functions and variance decompositions were approximated using 500 simulations as discussed by Thomas Doan and Robert Litterman (1986 p. 19-4).
}

TABLE 4-ForecAST-ERROR VARIANCE DECOMPOSITIONS: THREE-VARIABLEReal Model $(y, c, i)$, 1949:2-1988:4

\begin{tabular}{|c|c|c|c|}
\hline \multirow[b]{2}{*}{ Horizon } & \multicolumn{3}{|c|}{$\begin{array}{l}\text { Fraction of the forecast-error variance } \\
\text { attributed to the real permanent shock }\end{array}$} \\
\hline & $y$ & $c$ & $i$ \\
\hline 1 & $\begin{array}{c}0.45 \\
(0.28)\end{array}$ & $\begin{array}{c}0.88 \\
(0.21)\end{array}$ & $\begin{array}{c}0.12 \\
(0.18)\end{array}$ \\
\hline 4 & $\begin{array}{c}0.58 \\
(0.27)\end{array}$ & $\begin{array}{c}0.89 \\
(0.19)\end{array}$ & $\begin{array}{c}0.31 \\
(0.23)\end{array}$ \\
\hline 8 & $\begin{array}{c}0.68 \\
(0.22)\end{array}$ & $\begin{array}{c}0.83 \\
(0.18)\end{array}$ & $\begin{array}{c}0.40 \\
(0.18)\end{array}$ \\
\hline 12 & $\begin{array}{c}0.73 \\
(0.19)\end{array}$ & $\begin{array}{c}0.83 \\
(0.18)\end{array}$ & $\begin{array}{c}0.43 \\
(0.17)\end{array}$ \\
\hline 16 & $\begin{array}{c}0.77 \\
(0.17)\end{array}$ & $\begin{array}{c}0.85 \\
(0.16)\end{array}$ & $\begin{array}{c}0.44 \\
(0.16)\end{array}$ \\
\hline 20 & $\begin{array}{c}0.79 \\
(0.16)\end{array}$ & $\begin{array}{c}0.87 \\
(0.15)\end{array}$ & $\begin{array}{c}0.46 \\
(0.16)\end{array}$ \\
\hline 24 & $\begin{array}{c}0.81 \\
(0.16)\end{array}$ & $\begin{array}{c}0.89 \\
(0.13)\end{array}$ & $\begin{array}{c}0.47 \\
(0.16)\end{array}$ \\
\hline$\infty$ & 1.00 & 1.00 & 1.00 \\
\hline
\end{tabular}

Note: Based on an estimated vector error-correction model of $\mathbf{X}_{t}=\left(y_{t}, c_{t}, i_{t}\right)$ with eight lags of $\Delta \mathbf{X}_{t}$, one lag each of the error-correction terms $c-y$ and $i-y$, and a constant. Approximate standard errors, shown in parentheses, were computed by Monte Carlo simulation using 500 replications.

innovation eventually leads to a one-unit increase in $y, c$, and $i$.) In response to a shock that leads to a 1-percent permanent increase in $y, c$, and $i$, output and investment increase by more than 1 percent in the near term (1-2 years), while consumption moves less. Most of the adjustment is completed within four years. The results for $c$ and $i$ are consistent with the simple theoretical model discussed in Section I, where the capital stock rapidly increases at the shortrun cost of consumption.

Are these responses large enough to explain a substantial fraction of the short-run variation in the data? This key question is addressed in Table 4, which shows the fraction of the forecast-error variance at- 
tributed to innovations in the common stochastic trend, at horizons of 1-24 quarters. These variance decompositions suggest that innovations in the permanent component appear to play a dominant role in the variation of GNP and consumption. At the 1-4 quarter horizon, the point estimates suggest that 45-58 percent of the fluctuations in private GNP can be attributed to the permanent component. This increases to 68 percent at the two-year horizon and to 81 percent at the six-year horizon. The results for consumption are broadly similar. Notably, the permanent component explains a much smaller fraction of the movements in investment: only 31 percent at the one-year horizon, increasing to 47 percent at the six-year horizon.

This evidence suggests the existence of a persistent, potentially permanent, component that shifts the composition of real output between consumption and investment. (If there were temporary components with negligible effect on forecast errors after three or more years, then the population counterparts of the variance ratios in Table 4 would increase more sharply at the longer horizons.) Thus, the results motivate us to investigate the possibility of additional permanent components.

\section{Six-Variable Systems with Nominal Variables}

Augmenting output, consumption, and investment by real balances, nominal interest rates, and inflation yields a six-variable system. The results of Subsection III-B suggest that a reasonable specification incorporates three cointegrating relations (and thus three common trends) among the six variables. We have estimated a variety of six-variable models, with different numbers of trends, different cointegrating relations, and different orderings of the shocks. The detailed results for a benchmark model are reported in this subsection, and the results for the other models are summarized in the next subsection. The benchmark model incorporates the cointegrating relations $(c-y)=$ $\phi_{1}(R-\Delta p), \quad(i-y)=\phi_{2}(R-\Delta p), \quad$ and $m-p=\beta_{y} y-\beta_{R} R$. The first two relations link variation in the real ratios to permanent shifts in the real interest rate, although the estimates reported above suggest that this effect is small. The third implies that "money-demand" disturbances are $\mathrm{I}(0)$. The estimates of $\phi_{1}, \phi_{2}, \beta_{y}$, and $\beta_{R}$ are the restricted dynamic OLS estimates given in Table 2.

The permanent components and their impulse responses are identified by specifying a structure for the matrix of long-run multipliers. In the notation of Section II, with $\mathbf{X}_{t}=(y, c, i, m-p, R, \Delta p)^{\prime}$, the particular structure adopted is:

$$
\mathbf{A}=\left[\begin{array}{ccc}
1 & 0 & 0 \\
1 & 0 & \phi_{1} \\
1 & 0 & \phi_{2} \\
\beta_{y} & -\beta_{R} & -\beta_{R} \\
0 & 1 & 1 \\
0 & 1 & 0
\end{array}\right]\left[\begin{array}{ccc}
1 & 0 & 0 \\
\pi_{21} & 1 & 0 \\
\pi_{31} & \pi_{32} & 1
\end{array}\right] .
$$

The $6 \times 3$ matrix $\mathbf{A}$ is the matrix of long-run multipliers from the three permanent shocks. In the notation of Section II, the two matrices on the right-hand side of (8) are $\tilde{\mathbf{A}}$ and $\mathbf{I I}$, respectively.

Our interpretation of the shocks follows from the structure placed on the long-run multipliers in (8). The first shock is a realbalanced-growth shock, since it leads to a unit long-run increase in $y, c$, and $i$. Through the money-demand relation, it also leads to a $\beta_{y}$ increase in real balances. The second shock is a neutral inflation shock. It has no long-run effect on $y, c$, or $i$ and has a unit long-run effect on inflation and nominal interest rates. Further, the unit increase in nominal interest rates arising from this shock leads to reduction of real balances of $\beta_{R}$. The final permanent shock is a realinterest-rate shock. A one-unit increase in this shock leads to a change of $\phi_{1}$ and $\phi_{2}$ in $c-y$ and $i-y$. There is also a one-unit increase in nominal interest rates and a decrease of $\beta_{R}$ in real balances. The coefficients in $\Pi$ are determined by the requirement that the permanent innovations are mutually uncorrelated. In the standard VAR 
Table 5-Forecast-Error Variance Decompositions: Six-Variable Model (8), 1954:1-1988:4

\begin{tabular}{|c|c|c|c|c|c|c|}
\hline \multicolumn{7}{|c|}{ A. Fraction of the forecast-error variance attributed to balanced-growth shock } \\
\hline Horizon & $y$ & $c$ & $i$ & $m-p$ & $R$ & $\Delta p$ \\
\hline \multirow[t]{2}{*}{1} & 0.00 & 0.02 & 0.11 & 0.79 & 0.14 & 0.30 \\
\hline & $(0.13)$ & (0.09) & $(0.16)$ & $(0.23)$ & $(0.19)$ & $(0.13)$ \\
\hline \multirow[t]{2}{*}{4} & 0.05 & 0.15 & 0.06 & 0.76 & 0.11 & 0.22 \\
\hline & $(0.14)$ & $(0.13)$ & $(0.11)$ & $(0.23)$ & $(0.19)$ & $(0.08)$ \\
\hline \multirow[t]{2}{*}{8} & 0.22 & 0.31 & 0.14 & 0.70 & 0.11 & 0.20 \\
\hline & $(0.13)$ & $(0.18)$ & $(0.11)$ & $(0.24)$ & $(0.20)$ & $(0.07)$ \\
\hline \multirow[t]{2}{*}{12} & 0.44 & 0.48 & 0.27 & 0.72 & 0.11 & 0.17 \\
\hline & $(0.14)$ & $(0.21)$ & $(0.16)$ & $(0.25)$ & $(0.20)$ & $(0.06)$ \\
\hline \multirow[t]{2}{*}{16} & 0.54 & 0.59 & 0.32 & 0.74 & 0.11 & 0.16 \\
\hline & $(0.15)$ & $(0.21)$ & $(0.17)$ & $(0.24)$ & $(0.20)$ & $(0.07)$ \\
\hline \multirow[t]{2}{*}{20} & 0.59 & 0.63 & 0.33 & 0.75 & 0.12 & 0.15 \\
\hline & $(0.15)$ & $(0.19)$ & $(0.17)$ & $(0.22)$ & $(0.21)$ & $(0.07)$ \\
\hline \multirow[t]{2}{*}{24} & 0.62 & 0.65 & 0.33 & 0.77 & 0.14 & 0.14 \\
\hline & $(0.14)$ & $(0.17)$ & $(0.16)$ & $(0.22)$ & $(0.22)$ & $(0.08)$ \\
\hline$\infty$ & 1.00 & 0.92 & 0.97 & 0.78 & 0.23 & 0.04 \\
\hline \multicolumn{7}{|c|}{ B. Fraction of the forecast-error variance attributable to inflation shock } \\
\hline Horizon & $y$ & $c$ & $i$ & $m-p$ & $R$ & $\Delta p$ \\
\hline \multirow[t]{2}{*}{1} & 0.00 & 0.02 & 0.08 & 0.01 & 0.03 & 0.43 \\
\hline & $(0.12)$ & $(0.11)$ & $(0.16)$ & $(0.13)$ & $(0.14)$ & (0.19) \\
\hline \multirow[t]{2}{*}{4} & 0.04 & 0.01 & 0.23 & 0.04 & 0.04 & 0.37 \\
\hline & $(0.14)$ & $(0.10)$ & $(0.19)$ & $(0.14)$ & $(0.15)$ & $(0.13)$ \\
\hline \multirow[t]{2}{*}{8} & 0.04 & 0.01 & 0.20 & 0.01 & 0.02 & 0.36 \\
\hline & $(0.12)$ & $(0.11)$ & $(0.15)$ & $(0.14)$ & $(0.16)$ & $(0.12)$ \\
\hline \multirow[t]{2}{*}{12} & 0.03 & 0.01 & 0.12 & 0.01 & 0.02 & 0.45 \\
\hline & $(0.10)$ & $(0.12)$ & $(0.12)$ & $(0.14)$ & $(0.15)$ & $(0.11)$ \\
\hline \multirow[t]{2}{*}{16} & 0.02 & 0.01 & 0.10 & 0.01 & 0.03 & 0.49 \\
\hline & $(0.10)$ & $(0.12)$ & $(0.11)$ & $(0.13)$ & $(0.15)$ & $(0.11)$ \\
\hline \multirow[t]{2}{*}{20} & 0.02 & 0.02 & 0.10 & 0.01 & 0.03 & 0.53 \\
\hline & $(0.10)$ & $(0.12)$ & $(0.11)$ & $(0.13)$ & $(0.15)$ & $(0.12)$ \\
\hline \multirow[t]{2}{*}{24} & 0.02 & 0.02 & 0.09 & 0.01 & 0.02 & 0.55 \\
\hline & $(0.10)$ & $(0.11)$ & $(0.11)$ & $(0.13)$ & $(0.14)$ & $(0.13)$ \\
\hline \multirow[t]{2}{*}{$\infty$} & 0.00 & 0.02 & 0.00 & 0.00 & 0.01 & 0.96 \\
\hline & \multicolumn{6}{|c|}{ C. Fraction of the forecast-error variance attributable to real-interest-rate shock } \\
\hline Horizon & $y$ & $c$ & $i$ & $m-p$ & $R$ & $\Delta p$ \\
\hline \multirow[t]{2}{*}{1} & 0.67 & 0.35 & 0.44 & 0.03 & 0.63 & 0.00 \\
\hline & $(0.19)$ & $(0.22)$ & $(0.20)$ & $(0.13)$ & $(0.21)$ & $(0.11)$ \\
\hline \multirow[t]{2}{*}{4} & 0.74 & 0.24 & 0.50 & 0.07 & 0.72 & 0.10 \\
\hline & $(0.20)$ & $(0.18)$ & $(0.20)$ & $(0.14)$ & $(0.21)$ & $(0.08)$ \\
\hline 8 & 0.55 & 0.12 & 0.37 & 0.20 & 0.77 & 0.16 \\
\hline & $(0.16)$ & $(0.10)$ & $(0.14)$ & $(0.17)$ & $(0.22)$ & $(0.09)$ \\
\hline 12 & 0.39 & 0.11 & 0.36 & 0.21 & 0.78 & 0.14 \\
\hline & $(0.11)$ & $(0.09)$ & $(0.12)$ & $(0.18)$ & $(0.22)$ & $(0.08)$ \\
\hline 16 & 0.32 & 0.09 & 0.37 & 0.20 & 0.78 & 0.13 \\
\hline & $(0.10)$ & $(0.09)$ & $(0.12)$ & $(0.17)$ & $(0.22)$ & $(0.07)$ \\
\hline 20 & 0.28 & 0.09 & 0.34 & 0.18 & 0.78 & 0.12 \\
\hline & $(0.09)$ & $(0.08)$ & $(0.12)$ & $(0.16)$ & $(0.22)$ & $(0.07)$ \\
\hline 24 & 0.25 & 0.10 & 0.34 & 0.16 & 0.77 & 0.11 \\
\hline & $(0.08)$ & $(0.08)$ & $(0.11)$ & $(0.15)$ & $(0.22)$ & $(0.07)$ \\
\hline$\infty$ & 0.00 & 0.06 & 0.03 & 0.21 & 0.77 & 0.00 \\
\hline
\end{tabular}

Notes: Based on an estimated vector error-correction model of $\mathbf{X}_{t}=(y, c, i, m-p, R, \Delta p)$ with eight lags of $\Delta \mathbf{X}_{t}$, one lag each of the error-correction terms $c-y-\phi_{1}(R-\Delta p), i-y-\phi_{2}(R-\Delta p)$, and $m-p-\beta_{y} y+\beta_{R} R$ and a constant. Approximate standard errors, shown in parentheses, were computed by Monte Carlo simulation using 500 replications. 

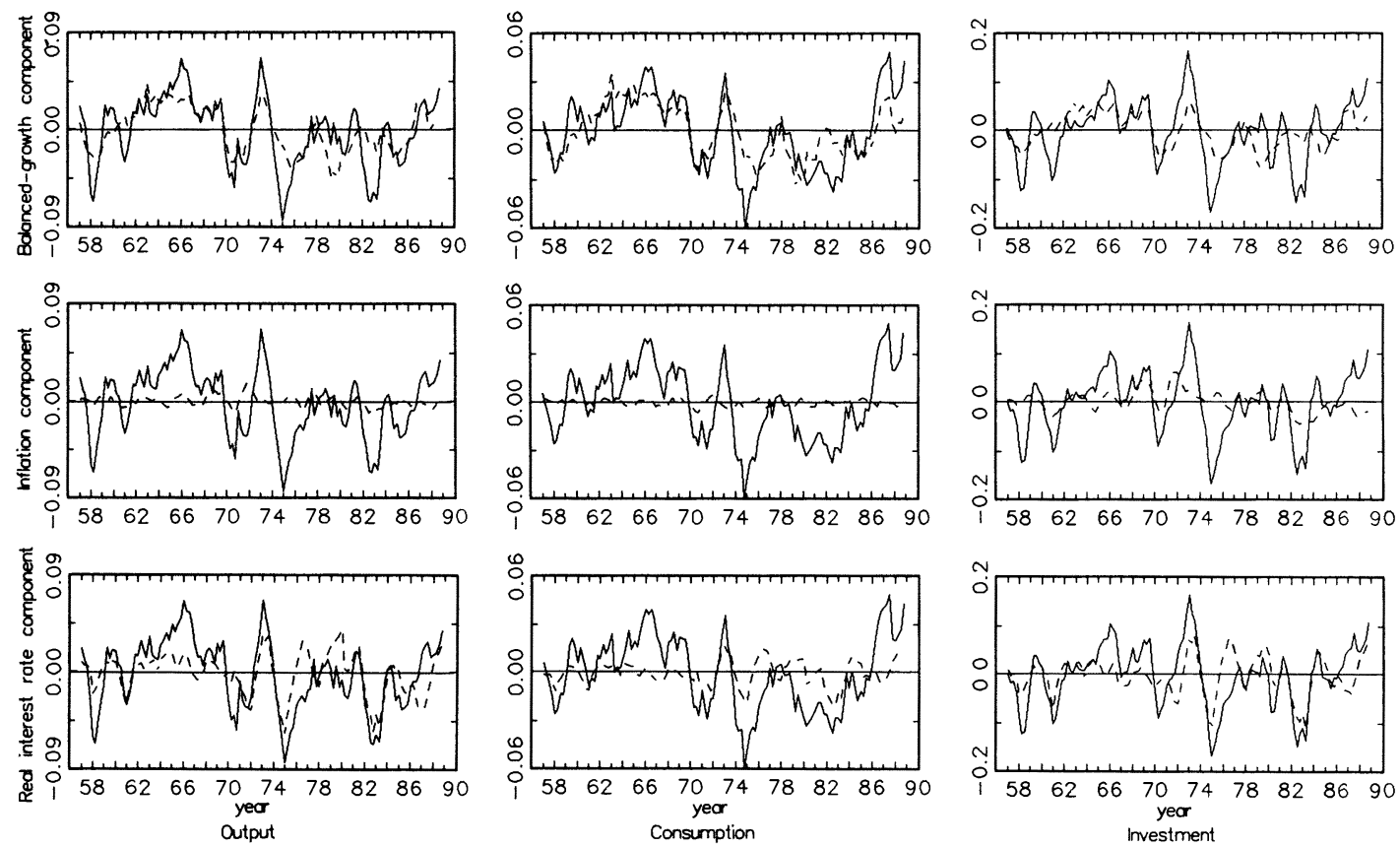

Figure 3. Historical Forecast-Error Decomposition in the Six-Variable Model

Note: The forecast errors are shown as percentages, on a decimal basis.

terminology, following Sims (1980), the balanced-growth disturbance is ordered first, the inflation disturbance is second, and the real-rate shock is third.

The model is estimated using a VECM with eight lags and the three error-correction terms implied by the cointegrating relations. Table 5 presents the variance decompositions of the forecast errors from the benchmark model. Four aspects of this table are of particular interest. First, relative to the three-variable model, the real or "balanced-growth" shock is less important for output and consumption, especially at the 1-4 quarter horizon. At the 3-5 year horizon, however, this shock has important explanatory power: roughly one-half the variation in these forecast errors is attributable to the first permanent component. Second, including the additional shocks in this expanded model does not enable the first permanent component to explain the short-run variations in investment. Third, the compo- nent associated with permanent shifts in the rate of inflation explains a considerable amount of the variation in inflation, but little else. Fourth, the component associated with permanent movements in the real interest rate explains most of the forecast errors in the nominal rate. It also is important for real activity: it explains substantial amounts of the output and investment forecast errors, particularly at the short horizons.

Figure 3 illustrates the roles played by the different shocks by plotting the forecast error at the three-year horizon and the portion attributable to each stochastic trend for $y, c$, and $i$. These plots highlight the negligible role of the inflation shock and the substantial role played by the balanced-growth shock and the real-interest-rate shock. Looking at specific episodes in this figure, one finds that the balanced-growth shock has particular explanatory power for the sustained growth of the 1960's. On the other 

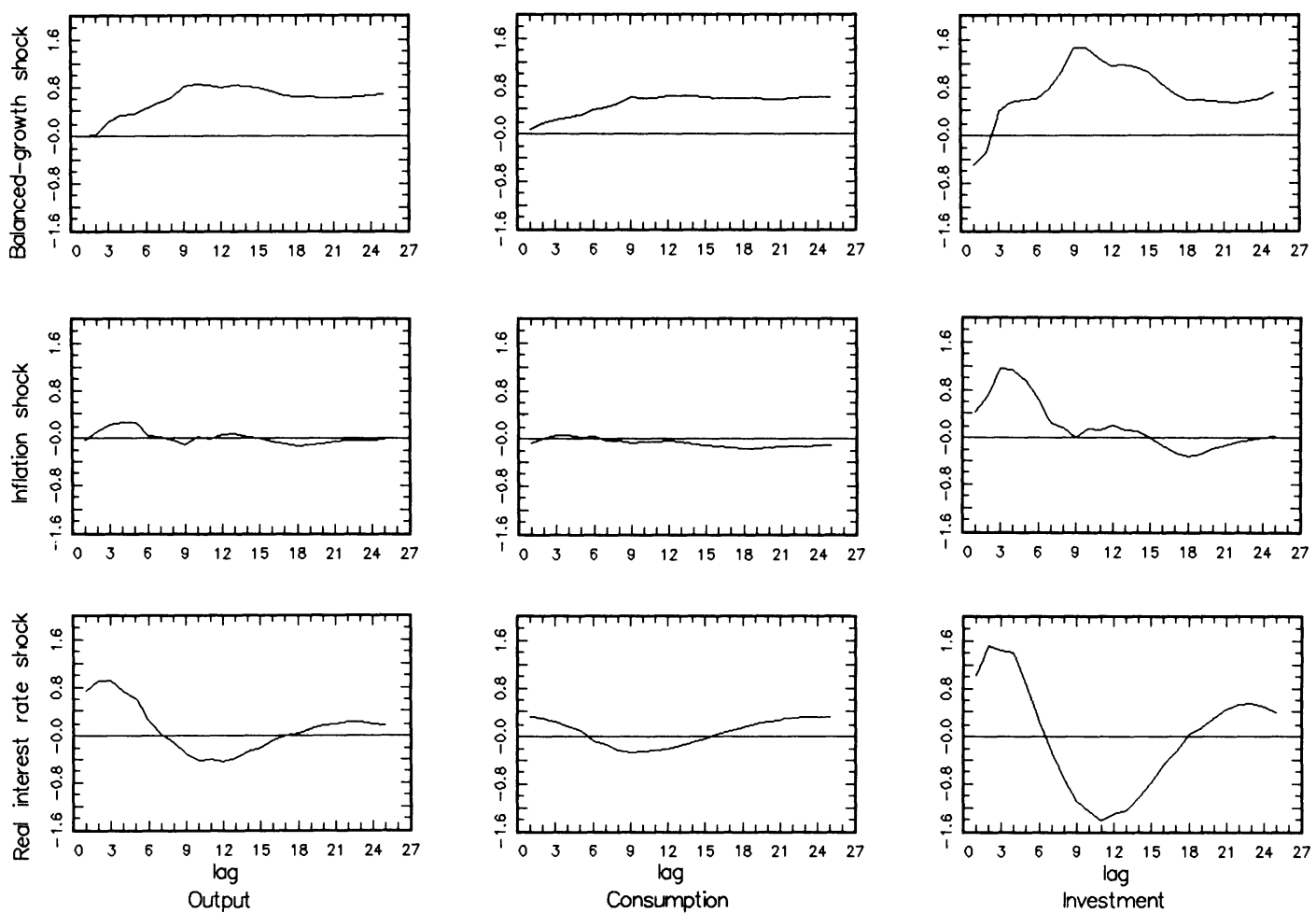

Figure 4. Response in the Six-Variable Model to a One-Standard-Deviation Shock in the Permanent Components

hand, the real-rate shock seems particularly important in the contraction of 1974 and the 1981-1982 recession.

Figure 4 shows the responses of the variables to one-standard-deviation impulses in the balanced-growth shock, the inflation shock, and the real-interest-rate shock. The estimated standard deviations of these underlying shocks are, respectively, 0.7 percent, 0.08 percent, and 0.12 percent per quarter. The response of output to the balanced-growth shock is negligible over the first few quarters, while consumption increases slightly and investment declines. After one year, major increases in output, consumption, and investment are present. While these responses are smaller than those in the three-variable model, they conform to how one might think a system would respond to news about technological developments. The inflation shock has very little impact on output and consumption. Investment, on the other hand, shows a large positive response to this shock for the first three quarters.

We have already noted that the realinterest-rate shock plays an important role in explaining the short-run behavior of output and investment. The impulse response functions make interpreting this shock as a permanent change in the real rate of interest somewhat difficult. All three of the real flow variables have an initial response to this shock that is strongly positive, before turning negative after 2-3 quarters. While there may be economic models that predict such responses to a permanent change in the real rate, standard ones do not.

We draw four conclusions from this analysis. First, permanent innovations account for a substantial fraction of transitory economic fluctuations. Second, the balanced- 
Table 6-Three-Year-Ahead Forecast-Error Variance Decompositions: SumMary of Results of VARIOUS MOdels

\begin{tabular}{|c|c|c|c|c|c|c|c|c|c|c|}
\hline \multirow[b]{2}{*}{ Model } & \multirow[b]{2}{*}{ Estimate period } & \multicolumn{3}{|c|}{$\begin{array}{c}\text { Tests of restrictions } \\
\text { on cointegrating vectors }\end{array}$} & \multicolumn{6}{|c|}{$\begin{array}{l}\text { Fraction of forecast-error } \\
\text { variance attributed to } \\
\text { the permanent real shock }\end{array}$} \\
\hline & & d.f. & Wald test $(P)$ & Log likelihood & $y$ & $c$ & $i$ & $m-p$ & $R$ & $\Delta p$ \\
\hline R.1 & 1949:2-1988:4 & 2 & $4.96(0.08)$ & $2,196.67$ & 0.73 & 0.83 & 0.43 & 一 & - & - \\
\hline M.1 & $1954: 1-1988: 4$ & 5 & $7.60(0.18)$ & $2,816.06$ & 0.44 & 0.48 & 0.27 & 0.72 & 0.11 & 0.17 \\
\hline M.2 & 1954:1-1988:4 & 7 & $12.60(0.08)$ & $2,814.64$ & 0.42 & 0.52 & 0.25 & 0.68 & 0.07 & 0.16 \\
\hline M.3 & $1954: 1-1988: 4$ & & same as M.1 & & 0.35 & 0.30 & 0.12 & 0.26 & 0.02 & 0.16 \\
\hline M.4 & 1954:1-1988:4 & 6 & $40.10(<0.01)$ & $2,820.48$ & 0.37 & 0.40 & 0.15 & 0.56 & 0.01 & 0.18 \\
\hline M.5 & $1954: 1-1988: 4$ & 4 & $3.04(0.55)$ & $2,812.52$ & 0.42 & 0.47 & 0.23 & 0.64 & 0.06 & - \\
\hline M.6 & $1954: 1-1988: 4$ & 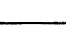 & same as M.5 & f & 0.42 & 0.36 & 0.19 & 0.46 & 0.01 & - \\
\hline
\end{tabular}

\section{Model Description}

Model R.1: $\quad$ Three-variable $(y, c, i)$ model with cointegrating relations $c-y$ and $i-y$

Model M.1: $\quad$ Six-variable $(y, c, i, m-p, R, \Delta p)$ baseline model of Table 5

Model M.2: Identical to M.1, except that the coefficients $\phi_{1}$ and $\phi_{2}$ are set to zero in the cointegrating vectors and the A matrix (i.e., cointegration of shares and the real interest rate is dropped)

Model M.3: Identical to M.1, except that the stochastic trend innovations are reordered to place the inflation shock first, the real-interest rate shock second, and the balanced-growth trend third

Model M.4: A two-stochastic-trend model for $(y, c, i, m-p, R, \Delta p)$, obtained by assuming that the real interest rate is stationary; the cointegrating relations are $c-y, i-y,(m-p)-\beta_{y} y+\beta_{R} R$ and $R-\Delta p$, and $\tilde{\mathbf{A}}=\left[\begin{array}{lll}\tilde{\mathbf{A}}_{1} & \tilde{\mathbf{A}}_{2}\end{array}\right]$, where $\tilde{\mathbf{A}}_{1}=\left(\begin{array}{lllll}1 & 1 & 1 & \beta_{y} & 0\end{array}\right)^{\prime}$ (balanced-growth shock) and $\tilde{\mathbf{A}}_{2}=$

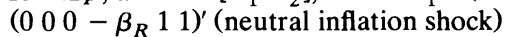

Model M.5: $\quad$ A five-variable system $(y, c, i, m-p, R)$ with cointegrating relations $c-y, i-y$, and $(m-p)-$ $\beta_{y} y+\beta_{R} R$, and $\tilde{\mathbf{A}}=\left[\begin{array}{lll}\tilde{\mathbf{A}}_{3} & \tilde{\mathbf{A}}_{4}\end{array}\right]$, where $\tilde{\mathbf{A}}_{3}=\left(\begin{array}{llll}1 & 1 & 1 & \beta_{y}\end{array}\right)^{\prime}$ (balanced-growth shock) and $\tilde{\mathbf{A}}_{4}=$ $\left(000-\beta_{R} 1\right)^{\prime}$ (neutral interest-rate shock)

Model M.6: Identical to M.5, except that the ordering of stochastic trend innovations is reversed, so $\tilde{\mathbf{A}}=$

$$
\left[\tilde{\mathbf{A}}_{4} \tilde{\mathbf{A}}_{3}\right]
$$

Notes: The estimation period denotes the sample used to estimate the VECM, with earlier data used for initial conditions for the lags. The Wald statistics, which test the hypothesis that the true cointegrating subspace is spanned by the hypothesized cointegrating vectors or, equivalently, that it is orthogonal to the $\mathbf{A}$ matrix, are computed using the dynamic OLS estimates and standard errors described in footnote 8.

growth factor retains a significant role in explaining movements at horizons greater than two years, although it has considerably less explanatory power in the six-variable system than in the three-variable system. Third, a large fraction of the short-run $(0-2$ year) variability in output and investment is explained by a factor that is related to persistent movements in the real rate of interest. Fourth, the impulse response functions appear to be consistent with the interpretation of the first shock as a real or balancedgrowth shock, but lead us to be uncertain about the interpretation of the third, realrate shock, at least within the context of standard macroeconomic models.

\section{E. Sensitivity Analysis}

It is important to explore the sensitivity of these main conclusions to changes in cointegrating vectors and changes in the ordering of the permanent components: we do this by estimating a variety of five- and six-variable models. To save space, we focus on a key measure, the fraction of the variance of the three-year-ahead forecast error in each variable explained by the balanced-growth permanent innovation. The results, summarized in Table 6, suggest four conclusions. First, looking across specifications, substantial fractions of the forecast errors in output and consumption are explained by the bal- 
anced-growth innovation; the point estimates range from one-third to two-thirds. Second, in systems including nominal variables, the fraction of the forecast-error variance of investment explained by the balanced-growth real permanent component is never large (at most 27 percent in model M.1). Third, little changes when balanced growth is imposed by setting $\phi_{1}$ and $\phi_{2}$ equal to zero. Fourth, changing the ordering of the shocks (e.g., putting the balanced-growth shock last in the Wold causal ordering, as in model M.3) does not change the main qualitative features of the results. In short, the sensitivity analysis indicates that the principal results for the base six-variable model are robust to a wide variety of changes in the identifying restrictions. ${ }^{12}$

\section{Analysis of Trend Components of Private GNP}

In the neoclassical growth framework of Section I, the common long-run movements in aggregate variables arise from changes in productivity. Is there any evidence that productivity movements are related to innovations in the balanced-growth component of GNP? We investigate this by comparing these estimated innovations to a popular estimate of the change in total factor productivity in the economy, Solow's (1957) residual. If the economy can be described by a Cobb-Douglas production function - as in the theoretical model of Section I-the Solow residual has the convenient interpretation of being exactly $\xi_{t}$ in (2). We use two measures of this productivity residual: Robert Hall's (1988 table 1) for total manufacturing and that produced by Prescott (1986). ${ }^{13}$

\footnotetext{
${ }^{12}$ Additional sensitivity analyses were performed: substituting short-term private and long-term public interest rates for the short-term public rate, dropping interest rates entirely, and changing the number of lags. The results, available from the authors on request, are consistent with the summary conclusions in this and subsequent sections.

${ }^{13}$ Because Hall's series is annual, Prescott's quarterly series was aggregated to an annual level.
}
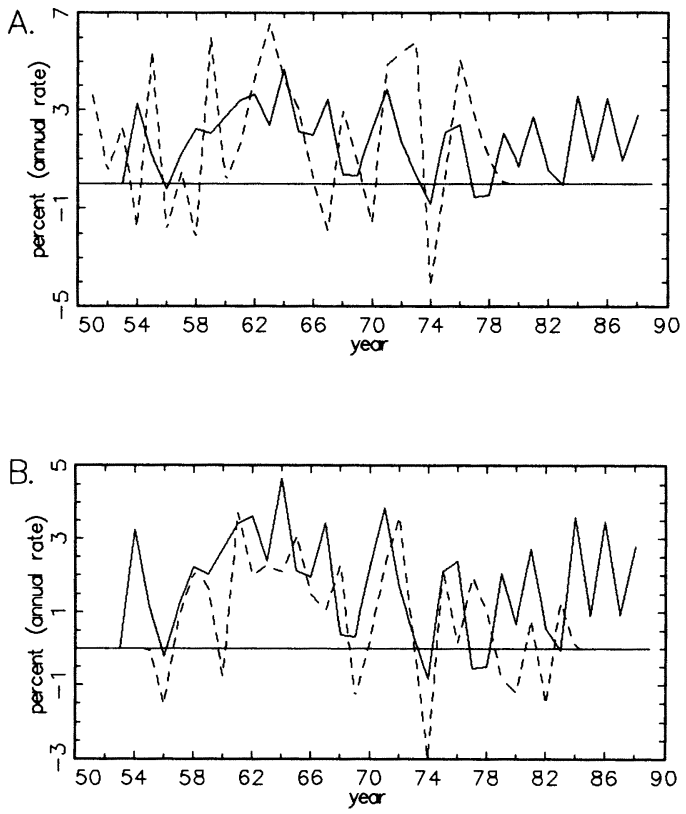

Figure 5. Balanced-Growth Shock from the Six-Variable Benchmark Model (Solid Line) AND A) Hall's Solow Residual or

B) Prescott's Solow Residual (Dashed Lines)

The time path of the Solow residual and the change in the balanced-growth-trend component of private GNP from the sixvariable model are plotted in Figure 5A for Hall's measure and in Figure 5B for Prescott's measure. The graphs suggest a very modest relation between Hall's Solow residual and our estimated balanced-growth shock (the correlation is 0.19 ) and a stronger relationship between Prescott's Solow residual and the estimated shock (the correlation is 0.48 ).

The Solow residual is an imperfect measure of technical change. For example, Prescott (1986) points to errors in measuring the variables used in its construction, and Hall (1988) suggests that this measure of productivity misrepresents true technological progress in noncompetitive environments where price exceeds marginal cost. Nonetheless, these results suggest some link between the real permanent shocks from the model and the two measures of the 


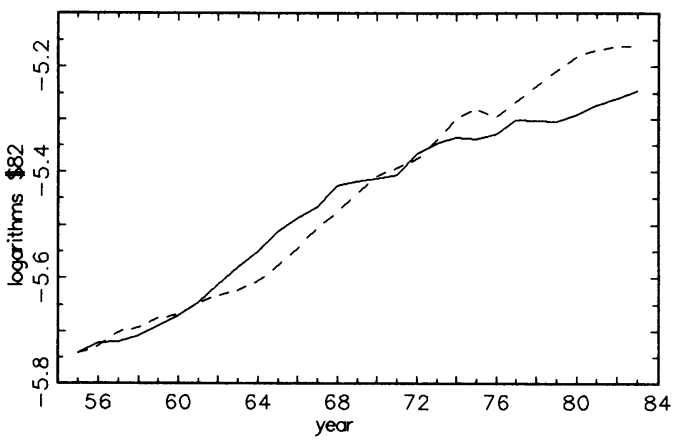

Figure 6. Estimates of Annual Trend OutPut: Denison's (1985 table 2-2) Estimate of Real Potential GNP Per Capita (Solid Line) ANd the Permanent Component of $y$ From the SiX-Variable Benchmark Model

(DASHEd Line)

Solow residual. These comparisons thus lend some credence to the interpretation in Section III of the permanent real shocks as measuring economy-wide shifts in productivity.

The focus so far has been to use the empirical model to evaluate a class of real-business-cycle models. However, the empirical model also provides a solution to a classic problem in descriptive economic statistics: how to decompose an economic time-series into a "trend" and a "cyclical" component. A natural definition of the trend is the long-run forecast of the variables (see Harvey, 1989 Ch. 6), and some simple algebra (see the Appendix) shows that changes in this trend are just linear combinations of the permanent innovations. Thus, the empirical model can be used to form a multivariate generalization of the trendcycle decomposition proposed by Stephen Beveridge and Charles Nelson (1981).

The implied trend component of output computed using the six-variable model is shown in Figure 6 along with Edward Denison's (1985) estimate of real potential GNP per capita. ${ }^{14}$ Despite the very different ap-

\footnotetext{
${ }^{1+}$ Denison computed his measure of potential output by adjusting actual output using an Okun's-law
}

proaches used to construct the two trend estimates, they are broadly similar. The three major differences between the two series are the prolonged growth of the 1960 's, the 1974 contraction, and the slowdown of the late 1970's.

\section{Conclusion}

In this paper, we have analyzed the stochastic trend properties of postwar U.S. macroeconomic data to evaluate the empirical relevance of standard RBC models with permanent productivity shocks. Several aspects of these results are consistent with the central proposition of most real-businesscycle models. Real per capita output, consumption, and investment (as well as real balances and interest rates) appear to share common stochastic trends. The cointegrating relations among the real flow variables are consistent with balanced growth; in addition, money, prices, output, and interest rates are consistent with a long-run moneydemand cointegrating relation. In a threevariable-real model, innovations in the balanced-growth component account for more than two-thirds of the unpredictable variation in output over the 2-5 year horizon.

Yet much evidence is at odds with onesector RBC models in which permanent productivity changes play a major role. Even in the three-variable model, the balancedgrowth innovation accounts for less than two-fifths of the movements of investment at horizons up to six years. The explanatory power of the balanced-growth innovation for output is reduced to less than 45 percent by introducing nominal variables. Moreover, the explanatory power arises mainly from some specific episodes, notably the sustained growth of the 1960's. The balancedgrowth innovation sheds little light on other important episodes, such as 1974-1975 and 1981-1982. Thus, we are led to conclude

relationship, by adjusting for capacity utilization and by making other adjustments such as for labor disputes, the weather, and the size of the armed forces (Denison, 1985 tables 2-4). 
that the U.S. data are not consistent with the view that a single real permanent shock is the dominant source of business-cycle fluctuations.

What are the omitted sources of the business cycle? From a monetarist perspective, it is surprising that such a small role is played by the inflation shock. Accelerations and decelerations in money growth and inflation, which are assumed to have no longrun effect on real flow variables and real interest rates, explain a trivial fraction of the variability in output and consumption and a small fraction of the variability in investment. The results point toward an additional permanent (or at least highly persistent) component associated with real interest rates which has large effects on investment.

\section{Appendix}

This appendix presents a discussion of identification and estimation. The definitions in the text are:

(A1) reduced form: $\Delta \mathbf{X}_{t}=\boldsymbol{\mu}+\mathrm{C}(\mathrm{L}) \boldsymbol{\varepsilon}_{t}$

(A2) structural model: $\Delta \mathbf{X}_{t}=\boldsymbol{\mu}+\boldsymbol{\Gamma}(\mathrm{L}) \boldsymbol{\eta}_{t}$.

The identifying restrictions are:

$$
\begin{gathered}
\boldsymbol{\Gamma}_{0} \boldsymbol{\eta}_{t}=\varepsilon_{t} \\
\Gamma(1)=[\tilde{\mathbf{A}} \boldsymbol{\Pi ~ 0}]
\end{gathered}
$$

where $\boldsymbol{\Gamma}_{0}^{-1}$ exists and where $\tilde{\mathbf{A}}$ is a known $n \times k$ matrix with full column rank, II is a $k \times k$ lower triangular matrix with full rank and 1's on the diagonal, and $\mathbf{0}$ is a $n \times(n-k)$ matrix of 0 's. The covariance matrix of the structural disturbances is assumed to be

$$
\boldsymbol{\Sigma}_{\eta}=E\left(\boldsymbol{\eta}_{t} \boldsymbol{\eta}_{t}^{\prime}\right)=\left[\begin{array}{cc}
\boldsymbol{\Sigma}_{\boldsymbol{\eta}^{1}} & 0 \\
0 & \boldsymbol{\Sigma}_{\boldsymbol{\eta}^{2}}
\end{array}\right]
$$

where $\boldsymbol{\Sigma}_{\eta}$ is partitioned conformably with $\boldsymbol{\eta}_{t}=\left(\boldsymbol{\eta}_{t}^{1,} \boldsymbol{\eta}_{t}^{2 \prime}\right)^{\prime}$, where $\boldsymbol{\eta}_{t}^{1}$ is a $k \times 1$ vector, $\eta_{t}^{2}$ is a $(n-k) \times 1$ vector, and where $\Sigma_{\eta^{1}}$ is diagonal.
Equations (A1) and (A2) are the definitions of the reduced form and structural models given in (5) and (6) in the text. Assumption (A3) says that the structural disturbances are in the space spanned by current and lagged values of $\mathbf{X}_{t}$ and that there are no singularities in the structural model. Assumption (A4) is discussed in the text explicitly for the six-variable model. It also applies to the three-variable model by defining $\tilde{\mathbf{A}}$ to be a vector of 1's. In Assumption (A4), the diagonal elements of $\Pi$ are normalized to unity without loss of generality, since the variances of $\boldsymbol{\eta}_{t}^{1}$, in (A5), are unrestricted.

The permanent innovations, $\boldsymbol{\eta}_{t}^{1}$, can be determined from the reduced form, (A1), as follows. From (A1)-(A3), $\mathbf{C}(\mathrm{L})=\boldsymbol{\Gamma}(\mathrm{L}) \boldsymbol{\Gamma}_{0}^{-1}$, so that $\mathbf{C}(1)=\boldsymbol{\Gamma}(1) \Gamma_{0}^{-1}$. Let $\mathbf{D}$ be any solution of $\mathbf{C}(1)=\tilde{\mathbf{A}} \mathbf{D}$ [for example, $\mathbf{D}=$ $\left.\left(\tilde{\mathbf{A}} \tilde{\mathbf{A}}^{\prime}\right)^{-1} \tilde{\mathbf{A}}^{\prime} \mathbf{C}(1)\right]$. Thus, $\tilde{\mathbf{A}} \mathbf{D} \boldsymbol{\varepsilon}_{t}=\tilde{\mathbf{A}} \boldsymbol{\Pi} \boldsymbol{\eta}_{t}^{1}$ and, since $E \boldsymbol{\eta}_{t}^{1} \boldsymbol{\eta}_{t}^{1 \prime}=\Sigma_{\boldsymbol{\eta}^{1}}, \mathbf{D} \boldsymbol{\Sigma}_{\mathbf{\varepsilon}} \mathbf{D}^{\prime}=\boldsymbol{\Pi} \boldsymbol{\Sigma}_{\boldsymbol{\eta}^{1}} \boldsymbol{\Pi}^{\prime}$. Let $\Pi^{*}$ be the unique lower triangular square root of $\mathbf{D} \Sigma_{\varepsilon} \mathbf{D}^{\prime}$, and let $\Pi$ and $\Sigma_{\eta}^{1}{ }^{1}$ be the unique solutions to $\Pi \Sigma_{\eta}^{1 / 2}=\Pi^{*}$, where $\boldsymbol{\Pi}$ and $\boldsymbol{\Sigma}_{\eta^{1}}$ satisfy (A4) and (A5). Then, $\mathbf{A}=$ $\tilde{\mathbf{A}} \boldsymbol{\Pi}$, and the first $k$ rows of $\boldsymbol{\Gamma}_{0}^{-1}$ are given by $\mathbf{G}=\boldsymbol{\Pi}^{-1} \mathbf{D}$. Since $\mathbf{D}$ is unique up to premultiplication by a nonsingular matrix, $\mathbf{G}$ is unique. Finally, $\boldsymbol{\eta}_{t}=\Gamma_{0}^{-1} \varepsilon_{t}$ implies that $\boldsymbol{\eta}_{t}^{1}=\mathbf{G} \varepsilon_{t}$.

The dynamic multipliers associated with $\boldsymbol{\eta}_{t}^{1}$ are given by the first $k$ columns of $\boldsymbol{\Gamma}(\mathrm{L})$. These can be calculated as follows. First, write $\boldsymbol{\Gamma}_{0}=(\mathbf{H J})$, where $\mathbf{H}$ has dimensions $n \times k$ and $\mathbf{J}$ has dimensions $n \times(n-k)$. Since $\boldsymbol{\Gamma}(\mathrm{L})=\mathbf{C}(\mathrm{L}) \boldsymbol{\Gamma}_{0}$, the first $k$ columns of $\boldsymbol{\Gamma}(\mathrm{L})$ are given by $\mathbf{C}(\mathrm{L}) \mathbf{H}$. Finally, $\boldsymbol{\varepsilon}_{t}=\boldsymbol{\Gamma}_{0} \boldsymbol{\eta}_{t}$ implies $\boldsymbol{\Sigma}_{\eta} \boldsymbol{\Gamma}_{0}^{\prime}=\boldsymbol{\Gamma}_{0}^{-1} \boldsymbol{\Sigma}_{\varepsilon}$, so that from (A5) $\mathbf{H}^{\prime}=\boldsymbol{\Sigma}_{\boldsymbol{\eta} 1}^{-1} \mathbf{G} \boldsymbol{\Sigma}_{\varepsilon}$; thus, the dynamic multipliers for $\boldsymbol{\eta}_{t}^{1}$ are $\mathbf{C}(\mathbf{L}) \boldsymbol{\Sigma}_{\mathbf{\varepsilon}} \mathbf{G}^{\prime} \boldsymbol{\Sigma}_{\boldsymbol{\eta} 1}^{-1}$.

Both the structural and reduced form lead naturally to the multivariate version of the Beveridge and Nelson (1981) decomposition used to estimate trend output, which is plotted in Figure 6. The structural form can be expressed as $\mathbf{X}_{t}=\mathbf{X}_{0}+\boldsymbol{\mu} t+\sum_{s=1}^{t} \boldsymbol{\Gamma}(\mathrm{L}) \boldsymbol{\eta}_{s_{1}}$ or, setting $\quad \mathbf{X}_{0}=\mathbf{0}, \quad \mathbf{X}_{t}=\boldsymbol{\mu} t+\Gamma(1) \sum_{s=1}^{t} \boldsymbol{\eta}_{s}^{1}+$ $\Gamma^{*}(\mathrm{~L}) \boldsymbol{\eta}_{t}$, where $\boldsymbol{\Gamma}_{j}^{*}=-\sum_{i=j+1}^{\infty} \boldsymbol{\Gamma}_{i}$. Let $\boldsymbol{\tau}_{t}=$ $\sum_{s=1}^{t} \boldsymbol{\eta}_{s}^{1}$; then, this becomes $\mathbf{X}_{t}=\mathbf{X}_{t}^{\mathrm{p}}+\mathbf{X}_{t}^{\mathrm{s}}$, where $\mathbf{X}_{t}^{\mathrm{s}}=\boldsymbol{\Gamma}^{*}(\mathrm{~L}) \boldsymbol{\eta}_{t}$ is the stationary component of $\mathbf{X}_{t}$ and $\mathbf{X}_{t}^{\mathrm{p}}=\boldsymbol{\mu} t+\Gamma(1) \sum_{s=1}^{t} \boldsymbol{\eta}_{s}^{1}=$ 
$\boldsymbol{\mu} t+\mathbf{A} \boldsymbol{\tau}_{t}$ is the permanent component of $\mathbf{X}_{t}$. By construction, $\mathbf{X}_{t}^{\mathrm{p}}$ satisfies the natural notion of a trend as the infinitely long-run forecast of $\mathbf{X}$, based on information through time $t$.

The only restrictions that the structural model places on the reduced form are the cointegration restrictions. This implies that efficient estimates of the structural model can be calculated in two steps: first, the reduced form is estimated imposing only the cointegration restrictions, and second, this estimated reduced form is transformed into the structural model using the relations given above. In all models reported in this paper, the reduced form was parameterized as a VECM (a cointegrated VAR). The estimated VECM was inverted to yield an estimate of the moving-average representation of the reduced form in (A1).

\section{REFERENCES}

Beveridge, Stephen and Nelson, Charles R., "A New Approach to Decomposition of Economic Time Series into Permanent and Transitory Components with Particular Attention to Measurement of the 'Business Cycle'," Journal of Monetary Economics, March 1981, 7, 151-74.

Blanchard, Olivier J. and Quah, Danny, "The Dynamic Effects of Aggregate Supply and Demand Disturbances," American Economic Review, September 1989, 79, 655-73.

and Watson, Mark W., "Are Business Cycles All Alike?" in R. J. Gordon, ed., The American Business Cycle: Continuity and Change, National Bureau of Economic Research Studies in Business Cycles, Vol. 25, Chicago: University of Chicago Press, 1986, pp. 123-82.

Cochrane, John H., "Univariate vs. Multivariate Forecasts of GNP Growth and Stock Returns: Evidence and Implications for the Persistence of Shocks, Detrending Methods, and Tests of the Permanent Income Hypothesis," NBER (Cambridge, MA) Working Paper, No. 3427, September 1990 .

and Sbordone, Argra M., "Multi- variate Estimates of the Permanent Components of GNP and Stock Prices," Journal of Economic Dynamics and Control, April 1988, 12, 255-96.

Dickey, David A. and Fuller, Wayne A., "Distribution of the Estimators for Autoregressive Time Series With a Unit Root," Journal of the American Statistical Association, June 1979, 74, 427-31.

Denison, Edward, Trends in American Economic Growth, 1929-1982, Washington, DC: The Brookings Institute, 1985.

Doan, Thomas A. and Litterman, Robert B., RATS User's Manual, Version 2.00, Evanston, IL: VAR Econometrics, 1986.

Engle, Robert F. and Granger, Clive W. J., "Cointegration and Error Correction: Representation, Estimation, and Testing," Econometrica, March 1987, 55, 251-76.

Fama, Eugene F., "Transitory Variation in Investment and Output," unpublished manuscript, University of Chicago, 1990.

Friedman, Benjamin M. and Kuttner, Kenneth N., "Money, Income, Prices and Interest Rates After the 1980's," Federal Reserve Bank of Chicago Working Paper 90-11, 1990.

Friedman, Milton, $A$ Theory of the Consumption Function, Princeton University Press: Princeton, NJ, 1957.

Hall, Robert E., "The Relationship Between Price and Marginal Cost in U.S. Industry," Journal of Political Economy, October 1988, 96, 921-47.

Hansen, Lars P. and Sargent, Thomas J., "Formulating and Estimating Dynamic Linear Rational Expectations Models," Journal of Economic Dynamics and Control, February 1980, 2, 7-46.

Harvey, Andrew C., Forecasting, Structural Time Series Models and the Kalman Filter, New York: Cambridge University Press, 1989.

and Stock, J. H., "Continuous Time Autoregressions with Common Stochastic Trends," Journal of Economic Dynamics and Control, April 1988, 12, 365-84.

Hoffman, Dennis $R$. and Rasche, Robert, "Long-Run Income and Interest Elasticities on Money Demand in the United States," NBER (Cambridge, MA) Discus- 
sion Paper No. 2949, 1989.

Johansen, Soren, "Statistical Analysis of Cointegration Vectors," Journal of Economic Dynamics and Control, April 1988, 12, 231-54.

King, Robert G., Plosser, Charles I. and Rebelo, Sergio T., "Production, Growth, and Business Cycles: II. New Directions," Journal of Monetary Economics, March 1988, 21, 309-42. , Stock, James H. and Watson, Mark W., "Stochastic Trends and Economic Fluctuations," NBER (Cambridge, MA) Discussion Paper No. 2229, April 1987.

and Rebelo, Sergio T., "Business Cycles with Endogenous Growth," working paper, University of Rochester, February 1988.

Kosobud, Robert and Klein, Lawrence, "Some Econometrics of Growth: Great Ratios of Economics," Quarterly Journal of Economics, May 1961, 25, 173-98.

Kydland, Fynn and Prescott, Edward C., "Time to Build and Aggregate Fluctuations," Econometrica, November 1982, 50, 1345-70.

Long, John B. and Plosser, Charles I., "Real Business Cycles," Journal of Political Economy, February 1983, 91, 39-69.

Lucas, Robert E., "Money Demand in the United States: A Quantitative Review," Carnegie - Rochester Conference on Public Policy, Autumn 1988, 29, 137-68.
Prescott, Edward C., "Theory Ahead of Business Cycle Measurement," CarnegieRochester Conference on Public Policy, Autumn 1986, 25, 11-66.

Sims, Christopher A., "Macroeconomics and Reality," Econometrica, January 1980, 48, 1-48.

, Stock, James H. and Watson, Mark W., "Inference in Linear Time Series Models with Some Unit Roots," Econometrica, January 1990, 58, 113-44.

Solow, Robert M., Growth Theory: An Exposition, Oxford: Clarendon Press, 1970. ,"Technical Change and the Aggregate Production Function," Review of Economics and Statistics, August 1957, 39, 312-20.

Stock, James H. and Watson, Mark W., "Testing for Common Trends," Journal of the American Statistical Association, December 1988, 83, 1097-1107. and , "A Simple MLE of Cointegrating Vectors in Higher Order Integrated Systems," NBER (Cambridge, MA) Technical Working Paper 83, 1989.

Wallis, Kenneth F., "Econometric Implications of the Rational Expectations $\mathrm{Hy}-$ pothesis," Econometrica, January 1980, 48, 49-74.

Board of Governors of the Federal Reserve System, Banking and Monetary Statistics, 1941-1970, Washington, DC: Board of Governors of the Federal Reserve System, 1976. 